\title{
Recent strategies targeting efficient hydrogen production from chemical hydrogen storage materials over carbon-supported catalysts
}

\author{
Miriam Navlani-García ${ }^{1}$, Kohsuke Mori ${ }^{1,2,3}$, Yasutaka Kuwahara ${ }^{1,3}$ and Hiromi Yamashita (B) ${ }^{1,3}$
}

\begin{abstract}
There is an evident urgent need to find a renewable and clean energy vector to ensure the worldwide energy supply while minimizing environmental impacts, and hydrogen stands out as a promising alternative energy carrier. The social concern around its safe storage is constantly fostering the search for alternative options to conventional storage methods and, in this context, chemical hydrogen storage materials have produced abundant investigations with particular attention to the design of heterogeneous catalysts that can boost the generation of molecular hydrogen. Among the chemical hydrogen storage materials, formic acid and ammonia-borane hold tremendous promise, and some of the recent strategies considered for the preparation of high-performance carbon-supported catalysts are summarized in this review. The outstanding features of carbon materials and their versatility combined with the tunability of the metal active phase properties (e.g., morphology, composition, and electronic features) provide numerous options for the design of promising catalysts.
\end{abstract}

\section{Introduction}

From the energy generation perspective, our current society is based on a carbon economy, which displays many weak points related not only to environmental issues, such as anthropogenically induced climate change associated with $\mathrm{CO}_{2}$ emissions from fossil fuels, but also to fossil fuel depletion, geographic location inequality, geopolitical tensions, and increasing worldwide energy demand caused by both the rapidly growing world population and the reasonable desire of inhabitants of less developed countries to increase their energy demand. Therefore, the search for a renewable and clean energy vector is mandatory to ensure sufficient worldwide energy

Correspondence: Kohsuke Mori (mori@mat.eng.osaka-u.ac.jp) or Hiromi Yamashita (yamashita@mat.eng.osaka-u.ac.jp)

'Division of Materials and Manufacturing Science, Graduate School of

Engineering, Osaka University, 2-1 Yamada-oka, Suita, Osaka 565-0871, Japan

2JST, PRESTO, 4-1-8 Honcho, Kawaguchi, Saitama 332-0012, Japan

Full list of author information is available at the end of the article supply while minimizing the environmental impact over the medium to long term. Among the great variety of alternative energy strategies, hydrogen holds tremendous promise as an energy carrier due to not only the flexibility associated with its production and use, but also its abundance on Earth $(\sim 0.9 \%$ by weight of the Earth's surface, being the ninth most abundant element in the Earth's crust $\left(1400 \mathrm{mg} \mathrm{kg}^{-1}\right.$ ) and the second most abundant element in the ocean after oxygen $\left(1.08 \times 10^{5} \mathrm{mg}\right.$ $\left.\mathrm{L}^{-1}\right)$ ) and its high chemical energy per mass (on a gravimetric basis) of $120 \mathrm{~kJ} \mathrm{~g}^{-1}$, which is approximately three times greater than that of petroleum ${ }^{1}$. Although the idea of using hydrogen as a fuel dates back to its isolation by Henry Cavendish in 1766, the concept of the "Hydrogen Economy" did not appear until $1923^{2}$. However, almost one century later, there are still major scientific, technical, and socio-economic challenges to overcome before the widespread implementation of a hydrogen economy ${ }^{1}$. In this regard, the cost of efficient and sustainable hydrogen 
production and delivery must be significantly reduced. Therefore, new hydrogen storage systems for both portable and stationary applications must be developed, and in addition, the cost of fuel cells must be reduced. Furthermore, unlike coal, gas, or oil, hydrogen is not a primary energy source itself; therefore, it is designated as an "energy carrier" or "energy vector" and its use is closely related to fuel cell technology ${ }^{3}$. Therefore, it is clear that fuel cells play a vital role in the hydrogen economy scenario and, even though they are still not widely available, there are already several applications in different areas, such as public transportation vehicles, submarines, or spacecraft $^{4}$. Currently, most hydrogen is generated industrially by methane reforming and by the water gas shift (WGS) reaction, but more steps are needed to diminish the remaining $\mathrm{CO}$ levels to below $10 \mathrm{ppm}$, which is the tolerance level of the Pt electrodes used in fuel cells ${ }^{5}$.

Apart from these major hurdles related to hydrogen generation, the issue of storage has received important attention, and the search for an efficient, safe, and commercially available storage option still constitutes a considerable challenge for the scientific community in the field of energy materials. The concern about safe and efficient hydrogen storage is emphasized by the fact that, even though the idea of using hydrogen as an energy vector in stationary applications could be visualized, currently, the main drive to use hydrogen as an energy vector comes from the possibility of replacing fossil fuel in portable devices, especially in the transportation sector. However, currently, 97\% of transportation fuel comes from crude oil, which is responsible for $\sim 25 \%$ of the global greenhouse emissions. Furthermore, the situation will be even worse in the near future as worldwide car use is experiencing exponential growth ${ }^{6}$. Meanwhile, considering the overall distribution (in approximate percentage) of the total global primary energy supply, carbon-based fossil fuels, such as oil and natural gas, account for more than $50 \%$ of the primary energy supply, while the distribution of other energy sources are much less significant (e.g., renewable $11 \%$, nuclear $7 \%$, and hydro-power $2 \%)^{6}$.

Hydrogen displays several advantages as an energy vector for use in transportation applications. It has the highest energy density by weight of any common fuel, it can be generated from renewable sources from a variety of non-fossil feed stocks, and it can be used in fuel cells to generate power with only water as a by-product ${ }^{7}$.

Hydrogen storage can be physical or chemical, depending on whether it is stored as molecular hydrogen $\left(\mathrm{H}_{2}\right)$ or as hydridic/protonic $\mathrm{H}$ combined with other elements (e.g., $\mathrm{B}, \mathrm{C}$, and $\mathrm{N}$ ), in which pressurized $\mathrm{H}_{2}$ and $\mathrm{H}_{2} \mathrm{O}$ are the most typical examples of these storage methods. Within the physical storage methods, three categories can be found: compressed gaseous hydrogen, liquid hydrogen, and adsorption on high-surface-area materials (e.g., carbon materials, organic polymers, zeolites, metal-organic frameworks (MOFs), and clathrate hydrates), but presently these storage technologies are far from efficient, and they are not yet affordable, safe, or lightweight ${ }^{8}$.

Chemical hydrogen storage can be divided into solid (metal hydride alloys, metal hydrides, complex hydrides, borohydrides, alanates, complex transition metal hydrides, amides, imides, and ammonia-borane) and liquid hydrogen storage media (liquid organic hydrogen carriers, hydrazine, alcohols, formic acid, and so on), and in both cases, the release of molecular hydrogen starts when the source material is subjected to thermal or catalytic decomposition ${ }^{9}$. The impact of chemical hydrogen storage materials in research has produced abundant investigations of the design of both homogeneous and heterogeneous catalysts able to boost the generation of molecular hydrogen from these molecules. In recent years, particular interest has been devoted to heterogeneous catalysts because they show several experimental advantages (easy separation, recycling, and mild operating conditions), which make them preferable for practical applications rather than the generally more efficient homogeneous catalysts. In this context, the design of supported metal nanoparticles (NPs) with tunable features is the cornerstone of the ongoing investigation aimed at preparing high-performance catalysts. Diverse supports (i.e., carbon, zeolites, MOF, and resins) have been widely explored to anchor metal NPs. These supports endow the final catalytic systems with stability, a high surface area, defined porosity, and possible metal-support interaction that will ultimately play a crucial role in the final catalytic behavior. Among the vast variety of materials explored thus far, carbon is unquestionably the most extensively studied support, not only for this particular application, but also for heterogeneous catalysis as a whole. Generally, the advantages of carbon materials are derived from the following characteristics: surface resistance to both basic and acid media, thermal stability, tunable pore structure, multiple macroscopic shapes (granules, fibers, powder, etc.), controllable polarity, and hydrophilicity by modifying the chemical surface properties and cost effectiveness ${ }^{10}$. In this review, we address several representative research advances in hydrogen generation from two of the most promising hydrogen storage materials, namely, formic acid and ammonia-borane, over carbon-supported metal NPbased catalysts.

\section{Formic acid}

Formic acid (FA), the simplest carboxylic acid, with the formula $\mathrm{HCOOH}$, was recognized as a potential hydrogen storage system in $1978^{11}$ and is currently considered one 


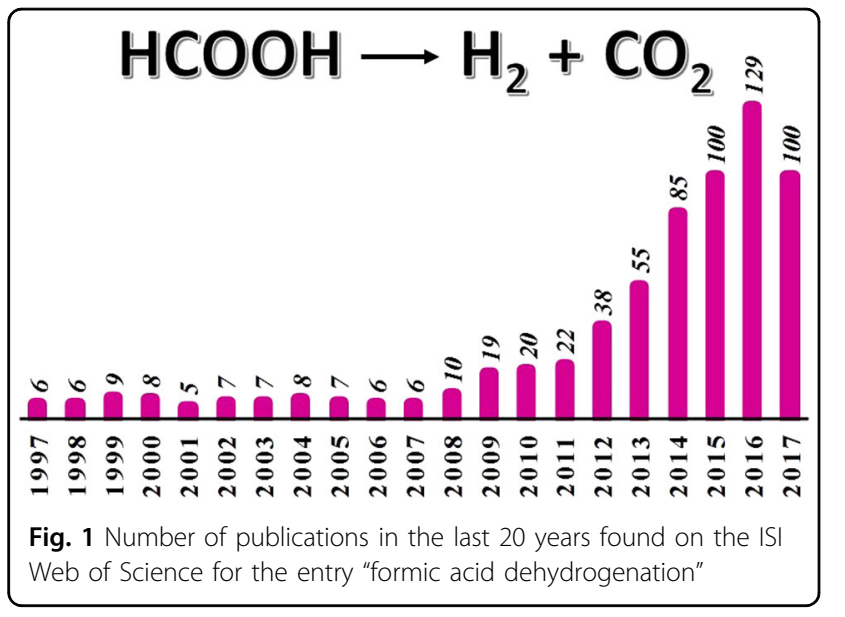

of the best materials for this application ${ }^{12}$. FA has a high volumetric hydrogen density of $53 \mathrm{~g} \mathrm{~L}^{-1}$, which is higher than the 2020 target of $40 \mathrm{~g} \mathrm{~L}^{-1}$ for onboard hydrogen storage for light-duty fuel cell vehicles updated by the U.S. Department of Energy (DOE) in May $2017^{13}$. Furthermore, advantageous properties such as its kinetical stability at room temperature, low-toxicity (median lethal dose, LD50 (oral, rat) value of $\left.1100 \mathrm{mg} \mathrm{kg}^{-1}\right)^{14}$ and suitability for easy transportation and handling, and safe storage, as well as its usable/net capacity, justify its research potential. The decomposition of FA proceeds by two pathways according to the following chemical equations:

Dehydrogenation : $\mathrm{HCOOH} \leftrightarrow \mathrm{H}_{2}+\mathrm{CO}_{2}, \Delta \mathrm{G}=-48.4 \mathrm{~kJ} \mathrm{~mol}^{-1}$

Dehydration : $\mathrm{HCOOH} \leftrightarrow \mathrm{CO}+\mathrm{H}_{2} \mathrm{O}, \Delta \mathrm{G}=-28.5 \mathrm{~kJ} \mathrm{~mol}^{-1}$

Literature documenting different approaches toward the preparation of efficient and selective catalysts for boosting FA decomposition by following the dehydrogenation pathway and avoid the generation of undesired $\mathrm{CO}$, has increased, especially over the last decade (see Fig. 1), but the development of heterogeneous catalysts achieving a competitive activity at low temperatures and a high selectivity is still a challenging task.

Among all the catalysts studied, those based on palladium have been reported to be very promising alternatives, not only because of their higher tolerance to $\mathrm{CO}$ than other metals, but also because relatively high hydrogen conversion and selectivity have been achieved under moderate temperatures. Thus, the research community interested in FA as a hydrogen carrier has devoted tremendous effort to understanding and optimizing Pdbased catalytic systems by enhancing either their performance under mild conditions or their stability and/or
Table 1 Catalytic performance of carbon-supported Pd catalysts in the FA dehydrogenation reaction

\begin{tabular}{|c|c|c|c|c|}
\hline Catalyst & Additive & $\mathrm{T}\left({ }^{\circ} \mathrm{C}\right)$ & TOF $\left(\mathrm{h}^{-1}\right)$ & Reference \\
\hline \multicolumn{5}{|l|}{ Monometallic } \\
\hline $\mathrm{Pd} / \mathrm{C}$ & HCOONa & 25 & $64^{\mathrm{a}}$ & 15 \\
\hline $\mathrm{Pd} / \mathrm{C}$ & $\mathrm{HCOONa}$ & 25 & $304^{b}$ & 16 \\
\hline $\mathrm{Pd} / \mathrm{CN}_{0.25}$ & None & 25 & $752^{\mathrm{b}}$ & 17 \\
\hline $\mathrm{Pd} / \mathrm{C}$ & HCOONa & 25 & $835^{\mathrm{b}}$ & 18 \\
\hline $\mathrm{Pd}-\mathrm{B} / \mathrm{C}$ & $\mathrm{HCOONa}$ & 25 & $1184^{\mathrm{b}}$ & 16 \\
\hline $\mathrm{Pd} / \mathrm{C}$ & $\mathrm{HCOONa}$ & 30 & $228.3^{\mathrm{a}}$ & 19 \\
\hline $\mathrm{Pd} /$ carbon black & HCOONa & 30 & $1815^{\mathrm{b}}$ & 20 \\
\hline $\mathrm{Pd} / \mathrm{N}-\mathrm{C}$ & HCOONa & 45 & 645 & 21 \\
\hline $\mathrm{Pd} / \mathrm{MSC}-30$ & $\mathrm{HCOONa}$ & 50 & $2623^{b}$ & 22 \\
\hline $\mathrm{Pd} / \mathrm{C}$ & $\mathrm{HCOONH}_{4}$ & 50 & $7959^{b}$ & 23 \\
\hline $\mathrm{Pd} / \mathrm{C}$ nanospheres & HCOONa & 60 & 7256 & 24 \\
\hline $\mathrm{Pd} / \mathrm{N}-\mathrm{MSC}-30$ & HCOONa & 60 & $8414^{b}$ & 25 \\
\hline \multicolumn{5}{|l|}{ Bimetallic PdAg } \\
\hline $\mathrm{Ag} @ P d / C(1: 1)$ & None & 20 & 192 & 26 \\
\hline $\mathrm{Pd}_{1} \mathrm{Ag}_{6} / \mathrm{N}-\mathrm{rGO}$ & None & 25 & $171^{\mathrm{b}}$ & 27 \\
\hline Ag@Pd/N-GCNT & None & 25 & $413^{\mathrm{a}}$ & 28 \\
\hline $\mathrm{Ag}_{74} \mathrm{Pd}_{26} /$ graphene & HCOONa & 25 & $572^{b}$ & 29 \\
\hline $\mathrm{AgPd} / \mathrm{C}$ & HCOONa & 30 & $854^{b}$ & 30 \\
\hline $\mathrm{C}-\mathrm{Ag}_{42} \mathrm{Pd}_{58}$ & None & 50 & $382^{b}$ & 31 \\
\hline $\mathrm{Pd}_{1} \mathrm{Ag}_{2} / \mathrm{C}$ & HCOONa & 75 & $855^{\mathrm{b}}$ & 32 \\
\hline \multicolumn{5}{|l|}{ Bimetallic PdAu } \\
\hline $\mathrm{Au}_{6} \mathrm{Pd}_{4} /$ carbon black & HCOONa & 0 & $635^{\mathrm{b}}$ & 33 \\
\hline $\mathrm{AuPd}-\mathrm{CeO}_{2} / \mathrm{N}-\mathrm{rGO}$ & None & 25 & $52.9^{\mathrm{b}}$ & 34 \\
\hline Au@Pd/N-mrGO & None & 25 & $89.1^{\mathrm{b}}$ & 35 \\
\hline $\mathrm{C}-\mathrm{Au}_{41} \mathrm{Pd}_{59}$ & None & 50 & $230^{b}$ & 36 \\
\hline $\mathrm{Pd}-\mathrm{Au}-\mathrm{Dy} / \mathrm{C}$ & $\mathrm{HCOONa}$ & 92 & 269 & 37 \\
\hline $\mathrm{Au}_{0.75} \mathrm{Pd}_{0.25} / \mathrm{C}-\mathrm{L}-7.5$ & HCOONa & 25 & $718^{b}$ & 38 \\
\hline $\mathrm{Au}_{6} \mathrm{Pd}_{4} /$ carbon black & HCOONa & 25 & $1075^{b}$ & 33 \\
\hline $\mathrm{Au}_{6} \mathrm{Pd}_{4}-\mathrm{L}-\mathrm{Mg}$ & HCOONa & 25 & $1120^{b}$ & 39 \\
\hline
\end{tabular}

a TOF calculated according to the volume of released $\mathrm{H}_{2}$ in overall testing time ${ }^{b}$ Initial TOF number

durability as well as selectivity. Some of the strategies tackled in this matter encompass the optimization of the active phase features in addition to the impact of the support properties in modulating the final catalytic behavior by controlling the metal-support interaction or the acid/base properties. In this section, representative studies on the recent approaches considered in the optimization of carbon-supported Pd-based catalysts will be summarized. 


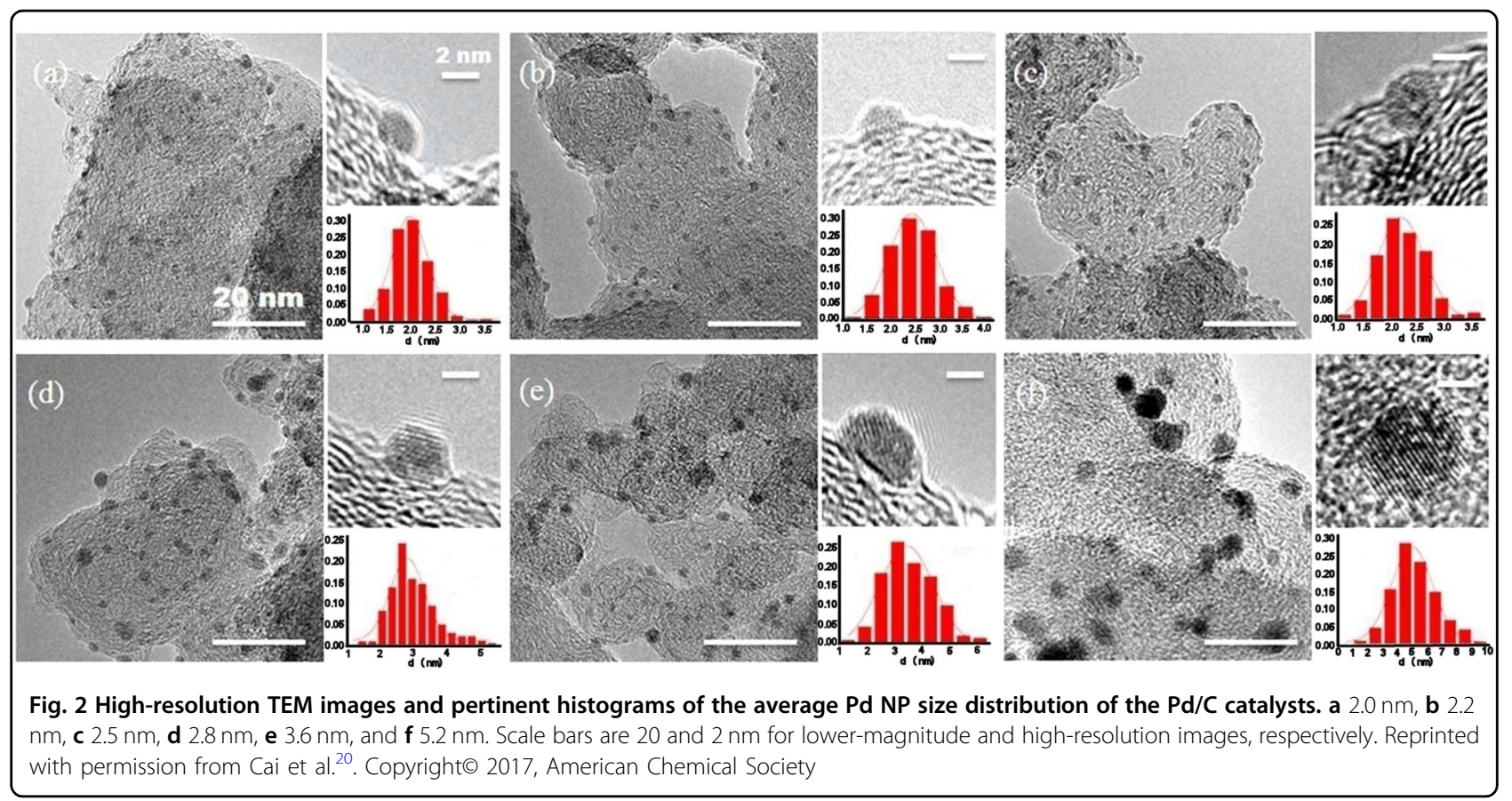

To give the readers a general idea of some of the catalysts studied to date, a selection of Pd-based catalysts and some of the experimental conditions used are listed in Table 1.

\section{Monometallic Pd-based catalysts}

The investigation of the active phase properties in the final catalytic performance is usually the cornerstone of the successful preparation of high-performance catalysts. For this reason, numerous aspects, such as NP size and electronic features, have been investigated by analyzing the importance of the tunability of the experimental conditions used in catalyst synthesis as well as the incorporation of additional functional groups on the carbonaceous support, among others.

In this regard, a recent study reported by Chung et al. ${ }^{40}$ addressed the importance of the preparation method in modifying the physicochemical properties of the metal phase and the carbon support. They performed a systematic study in which several experimental methods were used, such as adsorption of "ready-made" NPs, metal precursor adsorption + reduction, and metal precursor ion exchange + deposition + reduction. They found that the NP size, surface structure, and Pd electronic state are crucial aspects that must be considered. Furthermore, the catalytic behavior was also found to depend on the concentration and nature of the oxygen functional groups on the surface of the activated carbon.

Chen and coworkers recently published a study in which five Pd NP sizes (from 2.1 to $4.5 \mathrm{~nm}$ ) were analyzed, and under the experimental conditions used, the smallest
NPs displayed the best performance among those investigated (TOF of $835 \mathrm{~h}^{-1}$ ) 18 . Similarly, Cai and coworkers also addressed the size-dependent performance of carbon-supported Pd NPs for this application ${ }^{20}$. The control of the NP size in surfactant-free NPs was achieved by using several pH-adjusting agents $\left(\mathrm{Na}_{2} \mathrm{CO}_{3}, \mathrm{NaOH}\right.$, and $\mathrm{NH}_{3} \cdot \mathrm{H}_{2} \mathrm{O}$ ), which assisted the synthesis of NPs ranging from 2.0 to $5.2 \mathrm{~nm}$ in size (see Fig. 2). It was found that the best-performing sample was the $2.0 \mathrm{~nm} \mathrm{Pd} / \mathrm{C}$ catalysts, which attained an initial TOF of $1815 \mathrm{~h}^{-1}$.

$\mathrm{Xu}$ and coworkers ${ }^{24}$ also addressed the preparation of surfactant-free Pd NPs supported on carbon for this application by using anhydrous methanol as a solvent and a weak capping agent to control nucleation and avoid the aggregation of the Pd NPs. It resulted in the preparation of ultra-small metal NPs, which were subsequently immobilized on carbon spheres. That system displayed an excellent hydrogen production ability, with a TOF value of $7256 \mathrm{~h}^{-1}$. The same authors also developed a new synthetic protocol to synthetize a $\mathrm{N}$ containing porous carbon material, which was based on a tandem heat treatment with urea at different temperatures $^{25}$. The resulting support afforded the preparation of ultra-small and highly dispersed Pd NPs by a wet chemical impregnation and reduction method (see Fig. 3). The as-prepared catalysts displayed an outstanding performance in FA dehydrogenation, reaching $100 \%$ conversion in 0.35 min with a TOF of $8414 \mathrm{~h}^{-1}$ (calculated based on the total Pd loading), which is among the highest value reported so far for a heterogeneous catalyst in this application. 


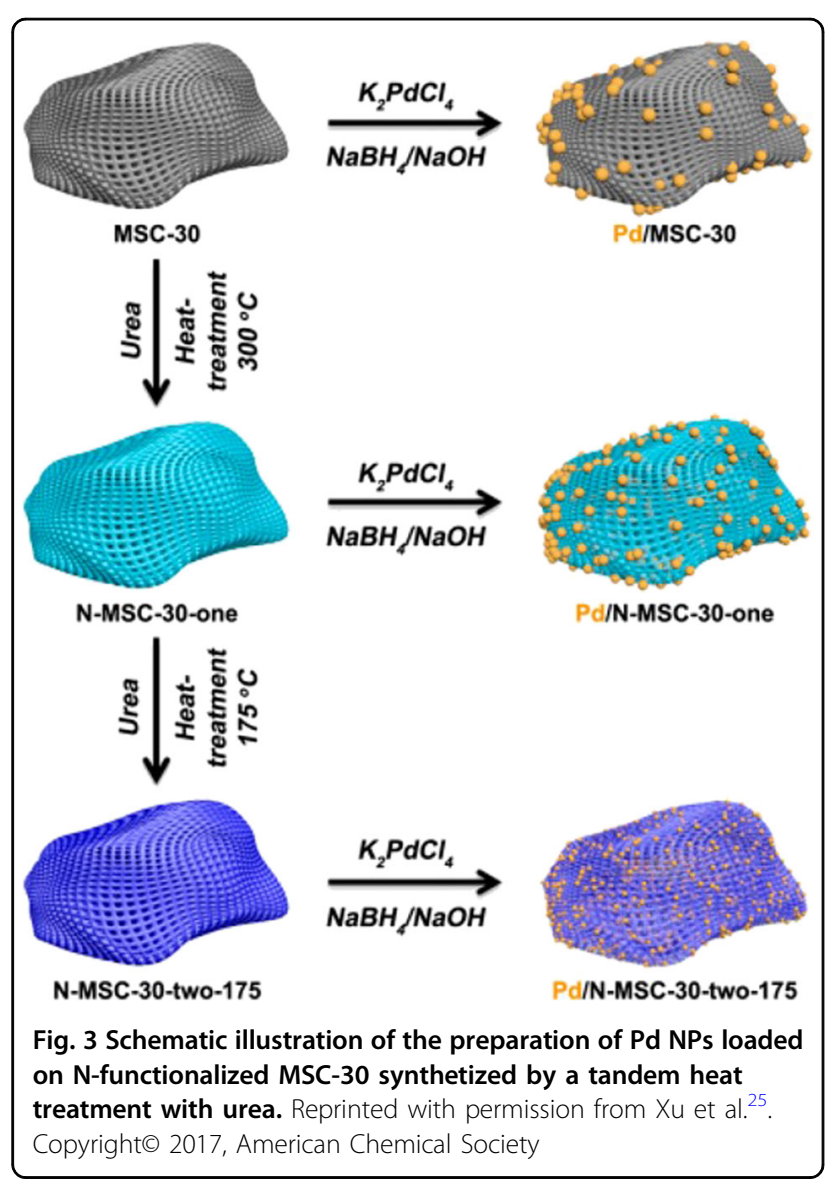

For N-doped carbon supports, Cao and coworkers ${ }^{17}$ recently addressed the impact of the electronic features of the Pd NPs on the final catalytic behavior, where the Pd surface electronic features and acid-base properties were modulated by the support properties. Mesoporous structures with a nanosheet-like morphology and a composition of $\mathrm{CN}_{\mathrm{x}}$ were synthetized by using a bio-chitosanbased pyrolysis strategy with melamine as the nitrogen source followed by a wet chemical reduction method using $\mathrm{PdCl}_{2}$. The resulting $\mathrm{Pd}$ species had a negative charge due to the interaction with the $\mathrm{N}$-group located on the carbon support. Apart from that contribution, Ndoping was expected to modify the surface Lewis base properties and, therefore, promote FA adsorption and the cleavage of the $\mathrm{O}-\mathrm{H}$ bond. However, the authors found in that study that the hydrogen production ability was not proportional to the nitrogen content, and the sample $\mathrm{Pd} /$ $\mathrm{CN}_{0.23}$ displayed the best performance among those investigated. To highlight the nitrogen effect, they performed XPS analysis of the $\mathrm{N} 1 \mathrm{~s}$, and three different $\mathrm{N}$ states, graphitic-, pyrrolic-, and pyridinic- $\mathrm{N}$, were determined in that case (see Fig. 4). Among them, pyridinic-N was believed to be the principal species responsible for the electronic interactions with Pd NPs, with the higher
pyridinic-N/Pd molar ratio found in sample $\mathrm{Pd} / \mathrm{CN}_{0.23}$ being responsible for its outstanding catalytic activity.

The beneficial effect of the electronic modification of $\mathrm{Pd}$ NPs induced by the N-doped carbon support was also under investigation by Jeon et al. ${ }^{21}$, whose study confirmed the importance of $\mathrm{N}$-functionalities in attaining small Pd NPs and electron-rich Pd species.

Pd catalysts supported on N-doped carbon were also the focus of a study by Bulushev et al. ${ }^{41}$. A goal of their research was to identify the nature of the active Pd species involved in the FA decomposition as well as their interaction with the $\mathrm{N}$-functional group on the support. A combined experimental and theoretical study was performed by using $\mathrm{N}$-free and $\mathrm{N}$-doped mesoporous carbon materials. The synthetic approach afforded a relatively high content of isolated $\mathrm{Pd}^{2+}$ cations stable during reduction due to their coordination to the pyridinic nitrogen species, which were claimed to be the active species for the FA decomposition reaction. This fact was confirmed by DFT calculations, which enabled the determination of the most energetically favorable $\mathrm{Pd}-\mathrm{N}$ structure.

The effect of additives in the FA-containing solution has merited several studies. Among them, sodium formate (HCOONa, SF) is the most widely addressed. Although the direct contribution of SF to the generation of hydrogen $\left(\mathrm{HCOO}^{-}+\mathrm{H}_{2} \mathrm{O} \rightarrow \mathrm{H}_{2}+\mathrm{HCO}_{3}{ }^{-}\right)$was reported to be almost negligible ${ }^{16}$, the adsorption of formate was proposed to promote the hydrogen production ability either by favoring the adsorption of FA on the catalysts ${ }^{42}$ or by being a reactive intermediate for its dehydrogenation ${ }^{43}$. Nevertheless, some authors, such as Jiang, found that SF acts not only as a catalyst promoter, but also as a source of hydrogen ${ }^{15}$. It was found that the volume of gas generated exceeded the theoretical value from FA dehydrogenation by $63 \mathrm{~mL}$, which was ascribed to the contribution of SF dehydrogenation over $\mathrm{Pd} / \mathrm{C}$. The molar ratio of FA/SF had a marked effect on the hydrogen production ability with the optimum mole percent of FA of $56 \%$.

Zhang and coworkers also investigated the effect of the addition of citric acid on the performance of $\mathrm{Pd} / \mathrm{C}$ catalysts in the FA/SF dehydrogenation ${ }^{19}$. In that case, the advantages provided by the addition of citric acid were demonstrated, since the production rate and yield of hydrogen attained by the catalyst prepared using citric acid was nearly twice that of the sample synthesized without it. As Jiang and coworkers found in their study ${ }^{15}$, the effect of the FA/SF ratio was also reported here, and $\mathrm{FA}: \mathrm{SF}=1: 9$ was the optimum value. The positive effect of the addition of SF was ascribed to the CO-free hydrogen generation from SF dehydrogenation in the presence of FA (Eqs. (3) and (4); overall reaction Eq. (5)), which resulted in enhanced performance compared to the pure FA solution, in which $\mathrm{CO}$ generated through FA 

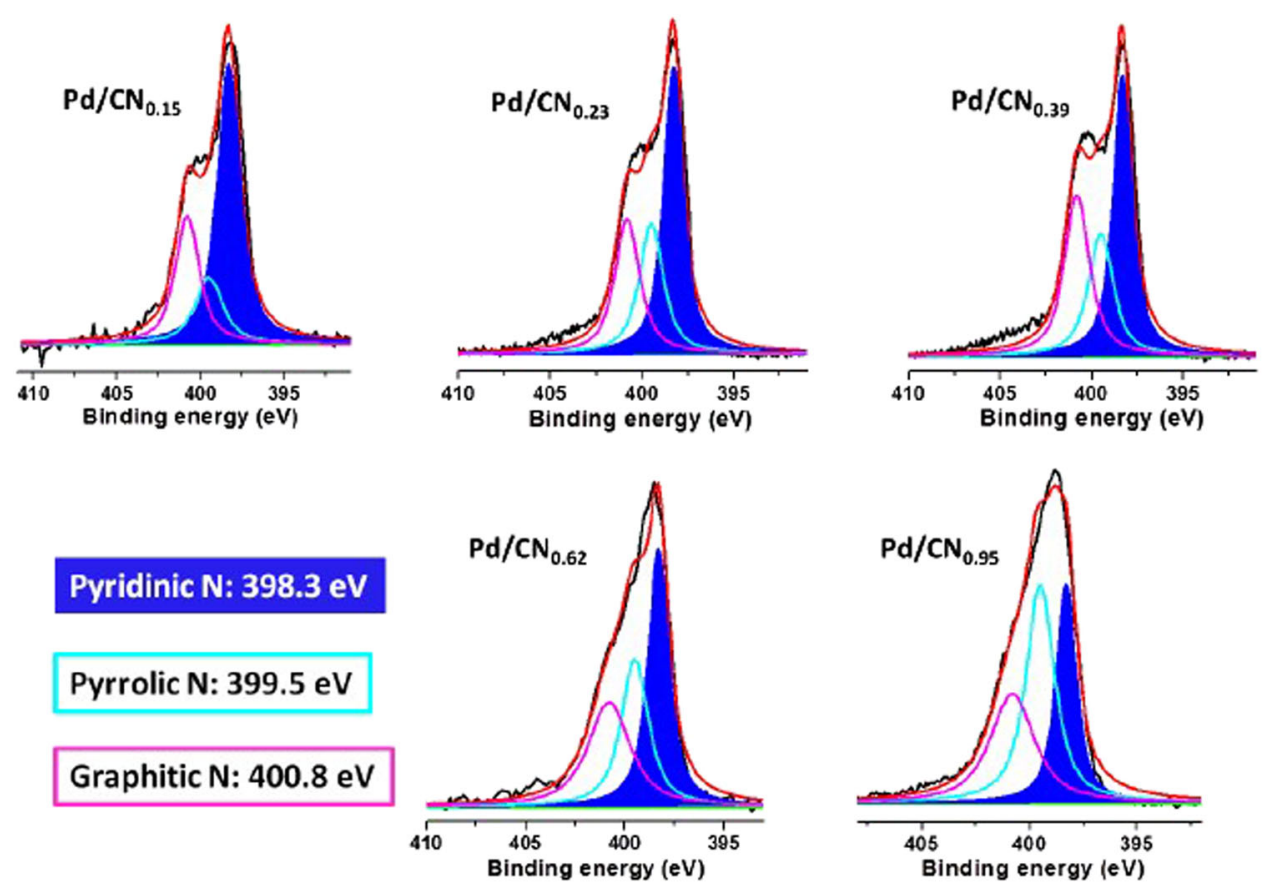

Fig. 4 XPS of the $\mathrm{N} 1 \mathrm{~s}$ for $10 \mathrm{wt} \% \mathrm{Pd} / \mathrm{CNx}$ (CNx was prepared from the combination of chitosan and melamine) catalysts. Reprinted with permission from Cao et al. ${ }^{17}$. Copyright 2016 WILEY-VCH Verlag GmbH \& Co. KGaA, Weinheim

dehydration (Eq. (6)) acted as a poison for the Pd-active sites and ultimately degraded the catalytic performance.

$$
\begin{aligned}
& \mathrm{HCOO}^{-}+\mathrm{H}_{2} \mathrm{O} \rightarrow \mathrm{HCO}_{3}^{-}+\mathrm{H}_{2} \\
& \mathrm{HCO}_{3}^{-}+\mathrm{HCOOH} \rightarrow \mathrm{HCOO}^{-}+\mathrm{H}_{2} \mathrm{O}+\mathrm{CO}_{2} \\
& \mathrm{HCOOH} \rightarrow \mathrm{H}_{2}+\mathrm{CO}_{2} \\
& \mathrm{HCOOH} \rightarrow \mathrm{H}_{2} \mathrm{O}+\mathrm{CO}
\end{aligned}
$$

Motivated by the enhanced performance observed from the addition of SF, as well as by the aforementioned incorporation of the N-groups on the carbon supports, Zhang investigated a formic acid-ammonium formate mixture (FA-AF) as an alternative to the widely used FA-SF system $^{23}$. To highlight the suitability of the FA-AF system vs. the traditional FA-SF, the catalytic performance using both mixtures was compared, and it was found that both the initial reaction rate and the volume of the gas generated by using the FA-AF mixture were much higher than those obtained with FA-SF. This finding helped the authors to conclude that the improved behavior of FA-AF was not only due to the catalytic activity of formate in the FA dehydrogenation, but also due to the effect of the adsorption of ammonia on the catalysts and the higher solubility of AF in the acid solution of FA.

In an attempt to enhance the catalytic performance, various additives in addition to the formate-based mixtures have been utilized thus far. For instance, Bulushev analyzed the effect of the addition of alkali metal carbonates $\left(\mathrm{CsCO}_{3}, \mathrm{~K}_{2} \mathrm{CO}_{3}\right.$, or $\left.\mathrm{Na}_{2} \mathrm{CO}_{3}\right)$ and lithium formate in FA dehydrogenation in the gas phase ${ }^{44}$. According to the obtained conversion profiles, doping with potassium carbonate was the most effective among those investigated. They further claimed that potassium carbonate reacts with FA to generate formate ions dissolved in the $\mathrm{FA} / \mathrm{H}_{2} \mathrm{O}$ solution condensed within the porosity of the material, and it acted as a buffer solution.

\section{Bimetallic Pd-based catalysts}

Despite the great achievements recently made in the investigation of monometallic Pd systems, their use has several problems that are mainly associated with the quick deactivation due to the poisonous intermediates, which can be alleviated by the use of bimetallic or multi-metallic systems. These systems usually display enhanced performances resulting from the electronic alteration of the $\mathrm{Pd}$ sites or, in some cases, from the weakened hydrogen adsorption on the NP surface, which ultimately would favor the combination of two hydrogen atoms to form a hydrogen molecule ${ }^{45}$.

Several metal combinations have been addressed so far in the literature, but PdAg and PdAu, in both bimetallic or multi-metallic systems, have certainly merited particular attention, and therefore, they will be the focus of this section. Nevertheless, for the sake of brevity, only some of the most representative works reporting on bimetallic systems will be mentioned. 

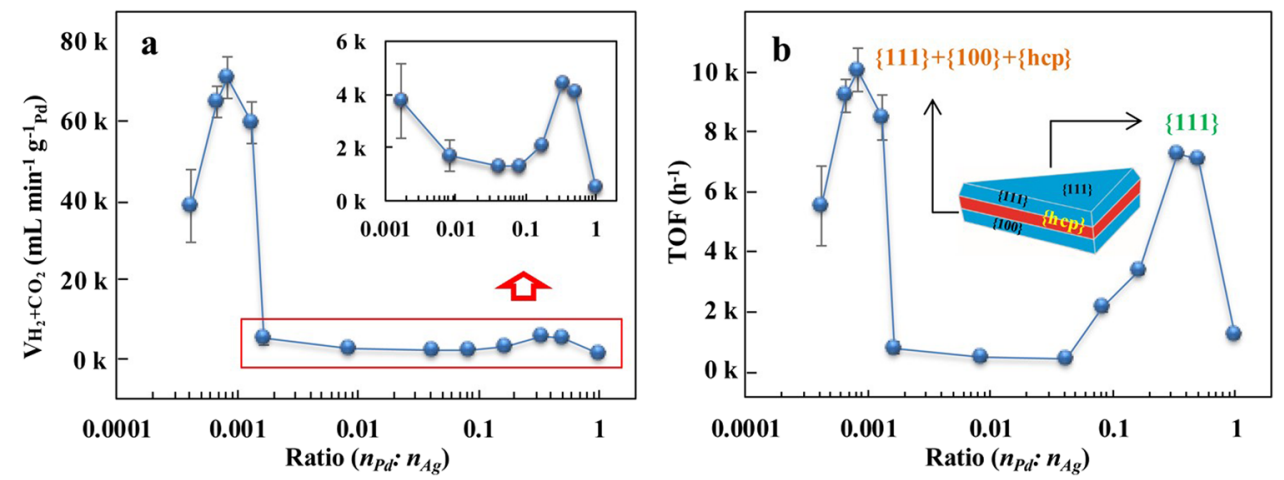

Fig. 5 Activity of Pd-Ag nanoplate catalysts for FA dehydrogenation under steady-state conditions at $90^{\circ} \mathrm{C}$ with different ratios of $n_{P d}$ : $\mathbf{n}_{\mathbf{A g}}$, expressed in two ways. a Volume rate per Pd weight. $\mathbf{b}$ TOF. The catalyst at each ratio of $\mathrm{n}_{\mathrm{Pd}}: \mathrm{n}_{\mathrm{Ag}}$ has $2-4$ parallel samples; their average performance is presented in this figure. The volume is at the standard situation. The TOF calculation is based on the Pd atoms on the nanoplate surface. Reprinted with permission from Zhou et al. ${ }^{47}$. Copyright@ 2016, American Chemical Society

\section{PdAg}

PdAg-based catalysts are greatly deserving of extensive investigations because they have been proven to be one of the most successful options for attaining a high activity toward the FA decomposition reaction. Their prominence over other bimetallic systems is linked to the important electronic promotion effect compared to other noble metals, which is due to the largest difference in the work function between $\mathrm{Pd}$ and $\mathrm{Ag}$ (5.6 and $4.7 \mathrm{eV}$, respectively) and the electron density enrichment of $\mathrm{Pd}$ due to the effective charge transfer from Ag.

One of the first studies reporting PdAg for FA decomposition at room temperature was published by Tedsree et $\mathrm{al}^{26}$. They employed the strategy of synthesizing coreshell bimetallic NPs to generate electronically modified Pd NPs, while preserving the desirable Pd surface features. The enhancement observed for this bimetallic system was attributed to the charge transfer from the Ag core to the $\mathrm{Pd}$ shell, which strengthens the adsorption of formate intermediates. The promising results obtained in that study motivated further investigations dealing with the optimization of PdAg systems.

The effect of the NP composition was checked by Cheng by testing alloyed AgPd/graphene catalysts with various compositions as well as their monometallic counterpart $^{46}$. It was found that the performance was not only NP composition dependent, but also influenced by the carbon material used as a support, and the graphenebased sample displayed better activity than the unsupported NPs or AgPd/Ketjen carbon. This result was attributed to the facilitated electron transfer and mass transport in graphene. Sun and coworkers ${ }^{31}$ also assessed the behavior of Ketjen carbon-supported AgPd NPs with various compositions, and the better activity of the bimetallic system was associated with their small size and the synergistic effect between $\mathrm{Ag}$ and $\mathrm{Pd}$ in the alloyed structure that inhibited the $\mathrm{CO}$ adsorption on $\mathrm{Pd}$, which was optimum in the case of the $\mathrm{Ag}_{42} \mathrm{Pd}_{58}$ sample.

An interesting study on facet-dependent activity was reported by Zhou and coworkers ${ }^{47}$. Bimetallic NPs were synthetized by depositing Pd onto $\mathrm{Ag}$ nanoplates with various facets $(\operatorname{Ag}\{111\}, \operatorname{Ag}\{100\}$, and the nano-facet on hexagonal close packing $\mathrm{Ag}$ crystal $\mathrm{Ag}\{\mathrm{hcp}\})$, and the resulting $\mathrm{Pd}-\mathrm{Ag}$ nanoplates were subsequently loaded on carbon black. The catalytic activity did not follow a linear relationship with the Pd content, but two activity peaks were present with the increase in Pd loading (see Fig. 5).

As detailed, each Ag nanoplate has a three-layer structure composed of two face-centered cubic (fcc) layers and a defect-induced hcp Ag crystal layer between them. The plates have a $\{111\}$ facet, and the edges have three facets including $\{111\},\{100\}$, and $\{\mathrm{hcp}\}$. Furthermore, the two maxima observed in the catalytic activity were related to the activity of the different facets on the planes and edges. The authors related the first peak activity (low $\mathrm{n}_{\mathrm{Pd}}: \mathrm{n}_{\mathrm{Ag}}$ ratio) to the average performance of three facets $(\mathrm{Pd}-\mathrm{Ag}$ $\{111\}, \operatorname{Pd}-\operatorname{Ag}\{100\}$, and $\mathrm{Pd}-\mathrm{Ag}\{\mathrm{hcp}\})$ and the second peak of activity (high $\mathrm{n}_{\mathrm{Pd}}: \mathrm{n}_{\mathrm{Ag}}$ ratio) to the performance of the $\mathrm{Pd}-\operatorname{Ag}\{111\}$ facet. After a detailed treatment of the results, it was concluded that the activity of these Pddecorated Ag nano-facets followed the order: $\mathrm{Pd}-\mathrm{Ag}$ $\{$ hcp $\}>\operatorname{Pd}-\operatorname{Ag}\{111\}>\operatorname{Pd}-\operatorname{Ag}\{100\}$.

Furthermore, for monometallic Pd systems, N-doped carbon materials have also been utilized as supports for bimetallic NPs. This was the approach of Etemadi et al. in which a N-doped graphene carbon nanotube aerogel was used as a support for Ag@Pd NPs (Ag@Pd/N-GCNT) ${ }^{28}$. In that case, the $\mathrm{Ag} / \mathrm{Pd}$ ratio was found to be optimum for sample $\mathrm{Ag}_{1} @ \mathrm{Pd}_{1} / \mathrm{N}-\mathrm{GCNT}$.

Apart from the classical carbon materials used as nanoparticle supports, studies reporting the utilization of MOF-derived carbon-based catalysts can be found in the 
recent literature. Wang and coworkers ${ }^{30}$ investigated a synergistic catalyst fabricated from AgPd bimetallic nanoparticles supported on carbon derived from MOF-5. The resulting materials showed high catalytic activity and selectivity toward FA dehydrogenation at ambient conditions with an initial TOF of $854 \mathrm{~h}^{-1}$, which was much higher than that achieved with the MOF-5-supported catalyst $\left(80 \mathrm{~h}^{-1}\right)$.

\section{PdAu}

The use of a $\mathrm{Pd}-\mathrm{Au}$ system in the FA decomposition reaction has attracted great attention since 2008, when Xing and coworkers successfully reported $\mathrm{Pd}-\mathrm{Au} / \mathrm{C}$ catalysts that were able to generate high-quality hydrogen from FA at $92^{\circ} \mathrm{C}^{48}$. The enhanced activity displayed by bimetallic systems was ascribed to a hindered $\mathrm{CO}$ adsorption on the bimetallic NP surface and the overcoming of a subsequent poisoning effect. Furthermore, they observed that the addition of $\mathrm{CeO}_{2}$ could further limit the adsorption of $\mathrm{CO}$ on the Pd surface and therefore promote its catalytic activity. This pioneering research led to many subsequent studies by that research groups and other authors.

One of the subsequent investigations conducted by the same group was on the promotion effect of three rare earth elements (Dy, Eu, and $\mathrm{Ho}$ ) on $\mathrm{Pd}-\mathrm{Au}$ / $C^{37}$. The promoting effect of the rare earth elements was due to the restoration of the $\mathrm{Pd}-\mathrm{Au} / \mathrm{C}$ catalysts due to the reaction of the oxygen species provided by the rare earth elements and the poisoning reaction intermediates.

As expected, the $\mathrm{Pd}-\mathrm{Au}$ ratio in the NPs was one possible factor. Sun and coworkers ${ }^{36}$ reported on the performance of Ketjen carbon-supported monodisperse 4 $\mathrm{nm}$ AuPd alloy NPs with controlled composition, and the $\mathrm{C}-\mathrm{Au}_{41} \mathrm{Pd}_{59}$ sample was the most active with an initial TOF $230 \mathrm{~h}^{-1}$ in the absence of additives. The stability of the catalyst was tested in a second run, and it was confirmed that the NPs preserved their Au and Pd composition and retained $89 \%$ of their initial activity.

Chen and coworkers reported on the synthesis of AuPd catalysts at a low temperature, and the low temperature was crucial for attaining small NPs. In an initial study ${ }^{33}$, low-temperature active $\mathrm{Au}-\mathrm{Pd}$ catalysts, which showed TOFs as high as $635 \mathrm{~h}^{-1}$ (at nearly $0{ }^{\circ} \mathrm{C}$ ), were synthetized. It was found that, in addition to the Pd content, the metal salt precursor reduction temperature played a crucial role in attaining well-distributed NPs on the carbon surface, which were responsible for the high activity. The average NP size was $2 \mathrm{~nm}$ for the sample prepared at the low temperature, while aggregates of up to $100 \mathrm{~nm}$ appeared in the sample synthetized at room temperature. Subsequently, they reported a new synthetic strategy based on a $\mathrm{Mg}^{2+}$-assisted low temperature $\left(-3^{\circ} \mathrm{C}\right)$ reduction

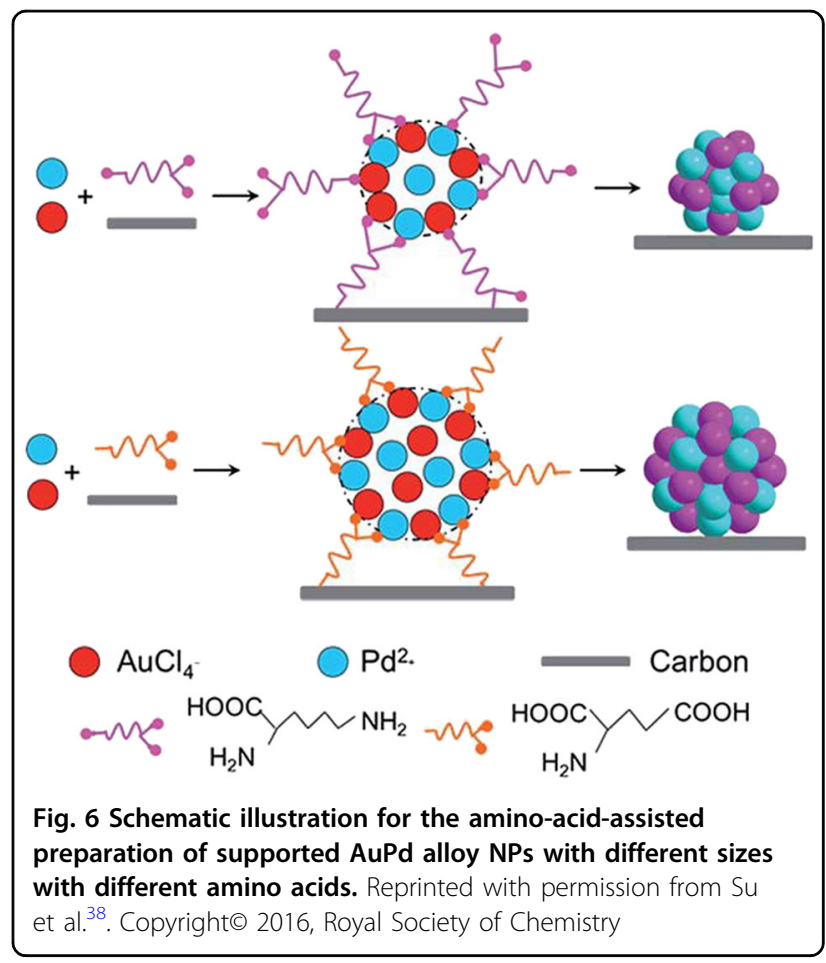

method $^{39}$. In that case, the significance of the low temperature in attaining small NPs with high activity was also confirmed, and the presence of $\mathrm{Mg}^{2+}$ was proved to further assist the preparation of small NPs and highperformance catalysts. The impact of the NP size was also studied by $\mathrm{Su}$ and coworker ${ }^{38}$ by synthesizing a set of $\mathrm{AuPd} / \mathrm{C}$ samples with the assistance of amino acids with different isoelectric points (lysine, serine, and glutamic acid) as structure-directing agents. The NP size depended on the different abilities of the amino acids toward immobilizing the NPs. In the case of lysine (basic), $\mathrm{NH}_{2}$ and $\mathrm{COO}^{-}$interacted with the ions of the metal precursors through electrostatic interactions and coordination bonds, and it produced small NPs by suppressing the motion of the reduced metal atoms. Furthermore, the ions of the metal precursor were weakly immobilized when glutamic acid was used, resulting in large NPs due to the non-alpha site of the carbon, while serine generated medium-sized NPs due to the absence of $\mathrm{NH}_{2}$ and undeprotonated $\mathrm{COOH}$ in the non-alpha site of carbon (see Fig. 6). The catalytic results revealed the superior performance of the sample prepared with lysine $\left(\mathrm{Au}_{0.75} \mathrm{Pd}_{0.25} / \mathrm{C}-\mathrm{L}-7.5\right)$, compared to those synthetized with serine, glutamic acid, and the amino acid-free counterpart.

Wang evidenced the role of the metal phase-support interaction in achieving small and well-dispersed AuPd NPs by preparing a composite graphene 
nanosheets-carbon black (GNs-CB) support ${ }^{49}$. The resulting NPs had a smaller size than those supported on pure $\mathrm{GNs}$ or $\mathrm{CB}(2.79,3.89$, and $4.03 \mathrm{~nm}$ for $\mathrm{Pd}-\mathrm{Au} /$ $\mathrm{GNs}-\mathrm{CB}, \mathrm{Pd}-\mathrm{Au} / \mathrm{CB}$, and $\mathrm{Pd}-\mathrm{Au} / \mathrm{GNs}$, respectively). Nevertheless, the improved catalytic activity achieved by $\mathrm{Pd}-\mathrm{Au} / \mathrm{GNs}-\mathrm{CB}$ was ascribed not only to the small NP size, but also to a marked anti-poisoning ability evidenced by $\mathrm{CO}$ stripping voltammetry experiments. Jiang also investigated the impact of the support properties by studying $\mathrm{N}$-doped graphene-supported $\mathrm{AuPd}-\mathrm{CeO}_{2}$ nanocomposites ( $\mathrm{AuPd}-\mathrm{CeO}_{2} / \mathrm{N}-\mathrm{rGO}$ ), and the existence of $\mathrm{N}$ atoms was crucial to the formation of ultra-fine and dispersed $\mathrm{AuPd}-\mathrm{CeO}_{2}$ nanocomposites ${ }^{34}$. Moreover, as shown by Xing and coworkers ${ }^{48}$, the importance of $\mathrm{CeO}_{2}$ was also highlighted.

\section{Ammonia-borane}

Ammonia-borane $\left(\mathrm{NH}_{3} \mathrm{BH}_{3}, \mathrm{AB}\right)$ is the simplest molecular boron-nitrogen-hydride compound, and it possesses high gravimetric and volumetric densities (196 $\mathrm{gH}_{2} \mathrm{~kg}^{-1}$ and $146 \mathrm{gH}_{2} \mathrm{~L}^{-1}$, respectively), a low molecular weight $\left(30.87 \mathrm{~g} \mathrm{~mol}^{-1}\right)$, non-toxicity, and a moderate decomposition temperature. It is a colorless molecular crystal under ambient conditions with a density of $0.74 \mathrm{~g}$ $\mathrm{cm}^{-3}$, and it is stable in air and soluble in water and other polar solvents ${ }^{50}$. These features, together with the multiple equivalents per main group element and the good match between the number of hydridic $\mathrm{B}-\mathrm{H}$ and protic $\mathrm{N}-\mathrm{H}$, make $\mathrm{AB}$ a successful $\mathrm{B}-\mathrm{N}$ hydrogen storage candidate $^{51}$, which stands out among most investigated materials.

The hydrogen stored in $\mathrm{AB}$ can be released via thermolysis (in the solid state) or metal catalyzed reaction (in protic solvents, such as water (catalytic hydrolysis) or methanol (methanolysis)) and, among them, hydrolytic dehydrogenation is the most extensively investigated alternative, as it can proceed under mild conditions in the presence of a suitable catalyst and affords $3 \mathrm{~mol}$ of

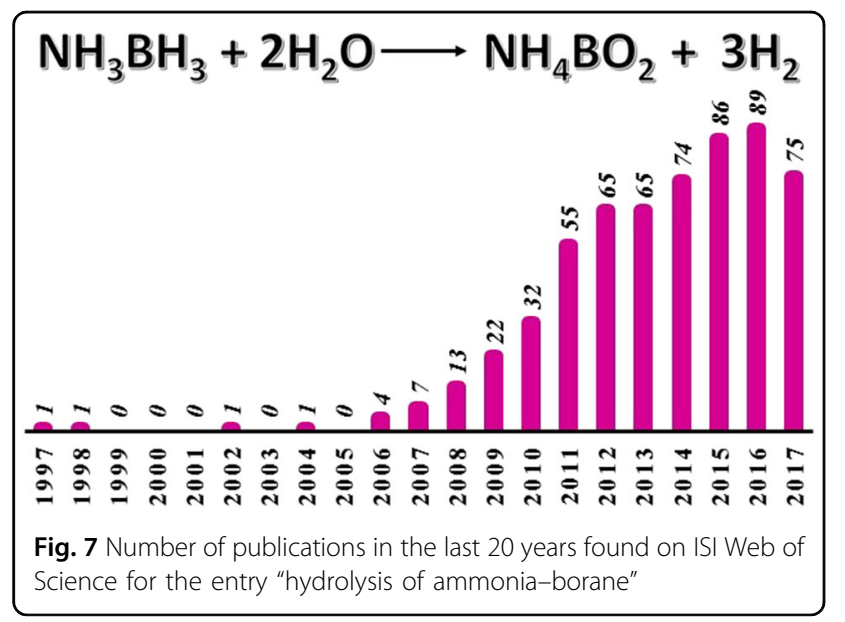

hydrogen per mol of $\mathrm{AB}$, according to Eq. (7):

$$
\mathrm{NH}_{3} \mathrm{BH}_{3}+2 \mathrm{H}_{2} \mathrm{O}(\mathrm{l}) \rightarrow \mathrm{NH}_{4} \mathrm{BO}_{2}+3 \mathrm{H}_{2}(\mathrm{~g})
$$

Although the investigation on hydrolysis of $\mathrm{AB}$ dates back to $1960^{52}$, thanks to the pioneer studies by Xu's group reporting complete $\mathrm{AB}$ hydrolysis in $2006^{53}$, the search for high-performance catalysts was fostered, and it is still a hot topic currently (see Fig. 7). In fact, while the supremacy of Pd-based heterogeneous catalysts in FA dehydrogenation is undeniable, the spectrum of active phases fruitfully investigated for $A B$ hydrolysis is much broader. For the carbon material support, carbon nanotubes (CNTs) seem to be preferred in this liquid phase reaction because they reportedly provide a high dispersion of NPs as well as a minimized diffusion limit and an increased contact surface area between the reactants and active phase compared to other carbon supports ${ }^{54}$. However, it is worth noting that in addition to carbon materials, there are a number of supports used for this application; due to the number of materials, it is beyond

Table 2 Catalytic performance of carbon-supported catalysts in the $\mathrm{AB}$ dehydrogenation reaction

\begin{tabular}{|c|c|c|c|}
\hline Catalyst & TOF $\left(\min ^{-1}\right)$ & $\mathrm{Ea}\left(\mathrm{kJ} \mathrm{mol}{ }^{-1}\right)$ & Reference \\
\hline \multicolumn{4}{|l|}{ Noble metal-based } \\
\hline Pt cube/CeO $2(7.0 \mathrm{~nm}) / \mathrm{RGO}$ & $48.0^{\mathrm{a}}$ & - & 55 \\
\hline $\mathrm{Pt} 20 / \mathrm{CNT}$ & $416.5^{\mathrm{a}}$ & 48.3 & 56 \\
\hline Pt/CNTs-O-HT & $567^{\mathrm{b}}$ & - & 57 \\
\hline Ru/graphene & $100^{\mathrm{a}}$ & 11.7 & 58 \\
\hline Ru(0)@MWCNT & $329^{\mathrm{a}}$ & 33 & 54 \\
\hline $\mathrm{Ru} / \mathrm{C}$ & $429.5^{a}$ & 34.81 & 59 \\
\hline Ru/graphene & $600^{\mathrm{a}}$ & 12.7 & 60 \\
\hline Ru/carbon thin film & $70.5^{\mathrm{b}}$ & 62 & 61 \\
\hline $\mathrm{Ru} / \mathrm{C}(800)$ & $670^{\mathrm{b}}$ & 14.3 & 62 \\
\hline $\mathrm{Ru}_{1} \mathrm{Cu}_{7.5} /$ graphene & $135^{\mathrm{a}}$ & 30.59 & 63 \\
\hline Ru@Ni/graphene & $339.5^{\mathrm{a}}$ & 36.59 & 64 \\
\hline \multicolumn{4}{|l|}{ Non-noble metal-based } \\
\hline Co@N-C-700 & $5.6^{\mathrm{a}}$ & 31.0 & 65 \\
\hline Co/NPCNW & $7.29^{\mathrm{a}}$ & 25.4 & 66 \\
\hline $\mathrm{PEI}-\mathrm{GO} 3 \mathrm{D} / \mathrm{Co}$ & $18.5^{\mathrm{a}}$ & 27.41 & 67 \\
\hline $\mathrm{Cu}_{0.49} \mathrm{Co}_{0.51} / \mathrm{C}$ & $28.7^{\mathrm{a}}$ & 51.9 & 68 \\
\hline $\mathrm{Cu}_{0.8} \mathrm{CO}_{0.2} \mathrm{O}-\mathrm{GO}$ & $70^{\mathrm{a}}$ & 45.53 & 69 \\
\hline Ni/CNTs (200 cycles) & $26.2^{\mathrm{a}}$ & 32.3 & 70 \\
\hline Ni@MSC-30 & $30.7^{\mathrm{a}}$ & - & 71 \\
\hline Ni NPs@3D-(N)GFs & $41.7^{\mathrm{a}}$ & - & 72 \\
\hline
\end{tabular}

a TOF calculated at $25^{\circ} \mathrm{C}$

b TOF calculated at $30^{\circ} \mathrm{C}$ 


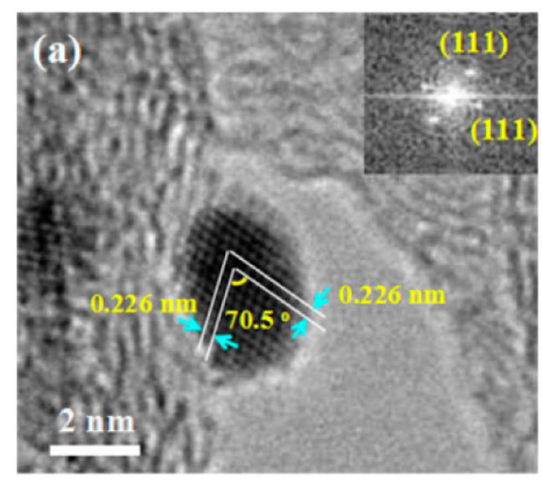

(b)
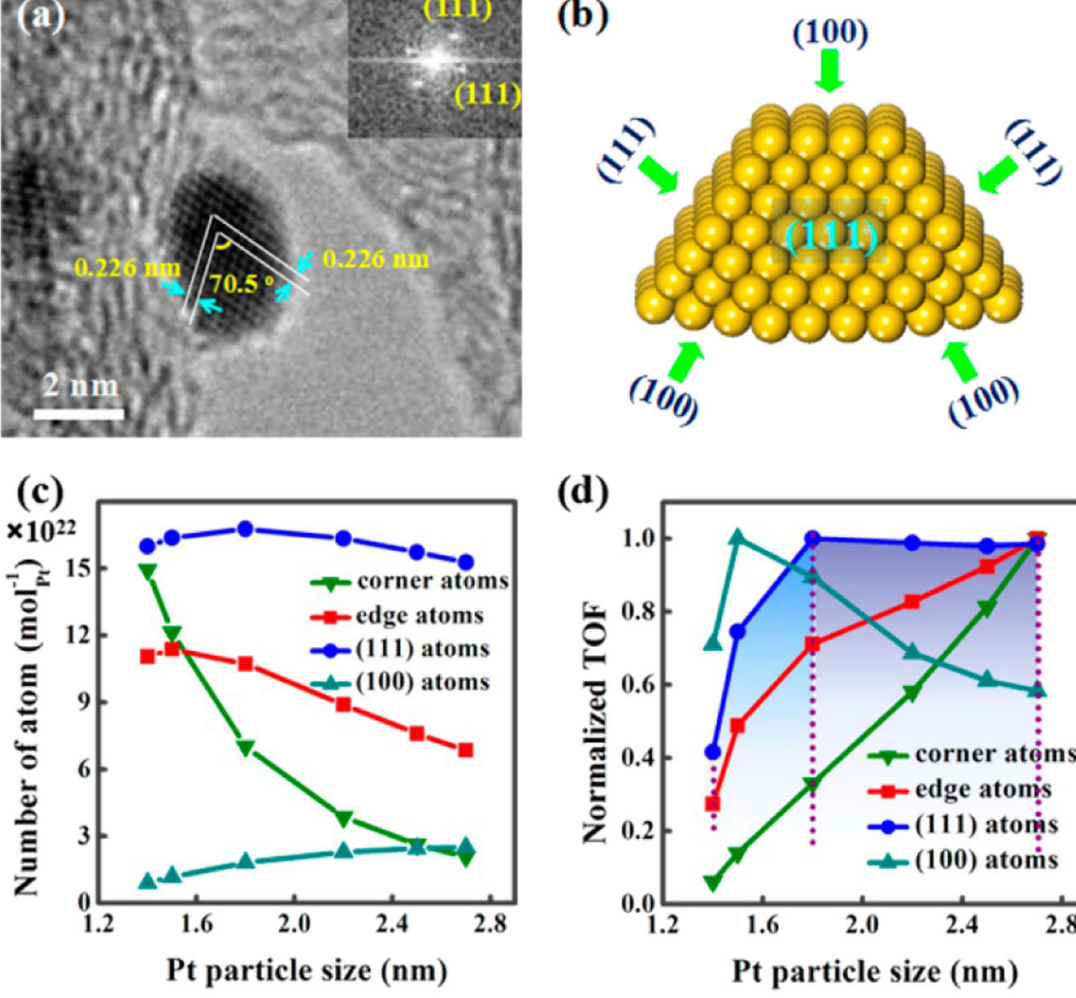

(d)

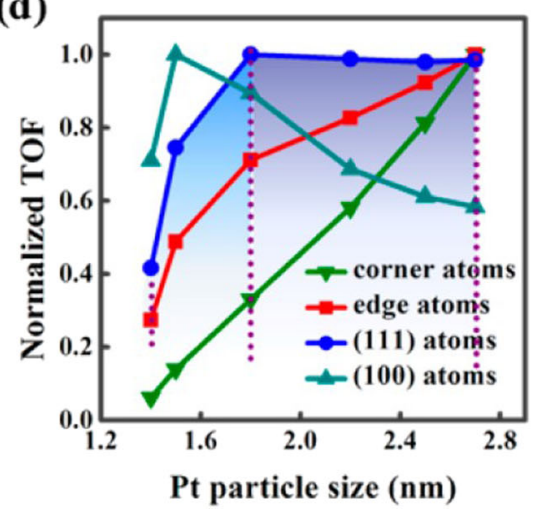

Fig. 8 HRTEM image of Pt NPs supported on CNT. a Typical HRTEM image of Pt nanoparticle supported on CNT. b Schematic diagram of truncated cuboctahedron. $\mathbf{c}$ Plots of the number of surface atoms per mole of Pt vs the Pt particle size of the truncated cuboctahedron. $\mathbf{d}$ Plots of the normalized TOF vs Pt particle size. Reprinted with permission from Yuan et al. ${ }^{74}$. Copyright@ 2014, American Chemical Society

the scope of this review, but recent literature in this field would provide a broader overview of the new achievements made in this field.

A glimpse into the most representative examples of carbon-supported catalysts used in the dehydrogenation of $\mathrm{AB}$ is listed in Table 2.

\section{Noble metal-based catalysts}

This group of catalysts was first found to display remarkable performance toward the dehydrogenation of $\mathrm{AB}$ and, among them, the suitability of Pt and Ru should be highlighted.

\section{Pt-based catalyst}

As previously mentioned, the use of catalysts supported on CNTs has been widely reported. Yuan demonstrated the supremacy of CNTs over activated carbon (AC) by comparing the performance of Pd/CNTs (with close CNTs) and $\mathrm{Pd} / \mathrm{AC}^{57}$. The support effect was ascribed to the difference in surface chemistry of both supports. In this sense, the electron donating oxygen groups were claimed to have a negative impact on the final performance, while the concentration of defects was positively affected. Then, the defect concentration on the CNT surface was further increased by acid oxidation followed by high-temperature treatment, and the resulting catalysts (Pt/CNTs-O-HT) displayed better performance than their untreated counterpart, confirming that the electrondeficient defects present on the CNT surface-assisted electron transfer from the Pt NPs to the carbon support. These Pt species were prone to forming the activated complex with $\mathrm{AB}$ molecules, therefore resulting in an enhanced $A B$ dehydrogenation ability.

A similar study was conducted by Zhou who investigated Pt catalysts supported on three kinds of carbon supports, namely, pristine CNTs (Pt/CNT-P), oxygengroup-rich CNTs (Pt/CNT-O), and defect-rich CNTs (Pt/ CNT-D $)^{73}$. Similarly, it was found that the supportdependent activity was due to the different electronic properties of $\mathrm{Pt}$, while the durability of the catalysts was linked to the adsorption of B-containing species on the NP surfaces.

Yuan's group reported the size-dependent activity and durability of Pt/CNT catalysts by synthetizing six catalysts with Pt NPs ranging in size from 1.4 to $2.7 \mathrm{~nm}^{74}$. The catalyst with $1.8 \mathrm{~nm}$ NPs displayed the optimum performance among those investigated, and the dominant effect of the (111) facets of Pt/CNT for AB dehydrogenation was 
demonstrated by calculating the normalized TOF values (see Fig. 8). Furthermore, the impact of the NP size on the durability of the catalysts was also evaluated in that study and was inversely proportional to the NP size, which was associated with the more favored adsorption of B-species on the small NPs together with their facility to undergo morphological changes under the reaction conditions.

To enhance the stability/durability of the catalysts in the $\mathrm{AB}$ dehydrogenation, Qin synthetized porous $\mathrm{TiO}_{2}-$ coated CNT-supported Pt catalysts ${ }^{56}$. Pt/CNT was synthetized by atomic layer deposition (ALD) and subsequently coated by porous $\mathrm{TiO}_{2}\left(\mathrm{TiO}_{2} / \mathrm{Pt} / \mathrm{CNT}\right)$. The samples prepared with various ALD cycles were assessed, and the catalysts prepared from 20 cycles (Pt20/CNT) corresponding to an average NP size of $1.86 \mathrm{~nm}$ showed better activity among those investigated. The $\mathrm{TiO}_{2}$-coated sample showed enhanced durability, retaining $60 \%$ of the initial activity after 10 catalytic runs, while only $40 \%$ was retained for the uncoated one.

\section{Ru-based catalyst}

Among the diversity of active phases utilized for this reaction, $\mathrm{Ru}$ catalysts are the most active ${ }^{62}$. As with Ptbased catalysts, CNTs have been reported as successful supports for this reaction. This was the case of Özkar and coworkers in their study on in situ-formed Ru NPs loaded on multiwalled carbon nanotubes $(\mathrm{Ru}(0) @ M W C N T)$, where the evolution of the $\mathrm{Ru}(0) \mathrm{NP}$ formation and concomitant $\mathrm{AB}$ dehydrogenation was monitored by following the change in $\mathrm{H}_{2}$ pressure ${ }^{54}$. The suitability of that system was attributed to the good dispersion of the NPs, as well as to the good accessibility of the surface of the NPs due to the small contact area between the NPs and the support. The positive impact of the MWCNT as a support was also demonstrated by Dou et al. by comparing the performance of Ru-supported MWCNTs, AC, and $\mathrm{SiO}_{2}$ synthetized by an electrostatic adsorption protocol. However, in that case, the high reaction rate displayed by $\mathrm{Ru} / \mathrm{MWCNTs}$ was related to the hydrogen spillover effect associated with a strong interface between $\mathrm{Ru}$ and MWCNTs ${ }^{75}$.

Cheng's group reported on the effect of the reducing agent for the synthesis of Ru NPs while studying the performance of $\mathrm{Ru}$ /graphene catalysts with $\mathrm{Ru} \mathrm{NPs}$ reduced by $\mathrm{NaBH}_{4}, \mathrm{AB}$, and methylamine borane ${ }^{58}$. The good performance displayed by the sample synthetized by methylamine borane was ascribed to the enhanced control of this reducing agent compared to the nucleation and growth process of Ru NPs over graphene. Furthermore, a better-performing $\mathrm{Ru}$ /graphene was synthetized by the same research group by the co-reduction of $\mathrm{RuCl}_{3}$ and graphite oxide in ethylene glycol using ascorbic acid as the reducing agent ${ }^{60}$. That catalyst showed a TOF number of $600 \mathrm{~min}^{-1}$. Soon after, our research group reported the investigation of $\mathrm{Ru} / \mathrm{C}$ catalysts synthetized by the impregnation of a $\mathrm{Ru}(\mathrm{bpy})_{3}{ }^{2+}$ precursor and its subsequent decomposition by heat treatment at temperatures ranging from 600 to $1000{ }^{\circ} \mathrm{C}$. Among them, the sample prepared at $800^{\circ} \mathrm{C}$ showed a TOF number of $670 \mathrm{~min}^{-1}$, which is among the highest values reported for the monometallic $\mathrm{Ru}$ catalysts in this reaction ${ }^{62}$. As with Cheng's group, Ma's group also reported the in situ synthesis of Ru NPs using carbon black as a support ${ }^{59}$. It was found that the high surface area of the carbon support (Ketjen black EC-300J, $800 \mathrm{~m}^{2} \mathrm{~g}^{-1}$ ) effectively stabilized the $\mathrm{Ru}$ nanoclusters and prevents them from agglomerating, assisting the preparation of small $(\sim 1.7 \mathrm{~nm}) \mathrm{NPs}$, regardless of the synthesis conditions ( $\mathrm{Ru}$ precursor concentration and temperature).

Some interesting results have also been reported for $\mathrm{Ru}$ bimetallic-based systems, such as $\mathrm{RuCu}^{63}$ or $\mathrm{RuNi}^{64}$.

\section{Non-noble metal-based catalysts}

The search for cost-effective catalysts is reflected in recent years in the increasing number of publications exploring the use of non-noble metal catalysts (both single and multicomponent) for the dehydrogenation of $\mathrm{AB}$. Some representative examples are summarized in this section.

\section{Co-based catalyst}

Although the suitability of Co-based catalysts toward $\mathrm{AB}$ dehydrogenation has been proven, the synthesis of stable and competitive catalysts for practical applications remains challenging. Recently, Co catalysts supported on modified carbon materials have been investigated. For instance, $\mathrm{Lu}$ and coworkers recently reported the synthesis of 3D-structured catalysts based on Co NPs loaded on branched polyethylenimine (PEI)-decorated graphene oxide (PEI-GO3D/Co) ${ }^{67}$. It was found that the 3D structure with a large and accessible surface area, together with the amine group of PEI, was positive for the stabilization of metal small NPs $(2-3 \mathrm{~nm})$, and the resulting catalyst attained complete hydrolysis of $\mathrm{AB}$ in $1 \mathrm{~min}$. Furthermore, the stability observed for that catalyst was also linked to the 3D structure of the support, which avoided the oxidation and aggregation of the Co NPs. A different and successful approach for the preparation of a stable Co-based catalyst was the use of $\mathrm{N}$-containing carbon materials as a support. In this context, Chen and coworkers ${ }^{65}$ reported the use of Co NPs embedded in porous $\mathrm{N}$-doped carbon (Co@N-C) synthetized via the one-step thermolysis of $\mathrm{Co}$ (salen) at selected temperatures $\left(600-800^{\circ} \mathrm{C}\right)$ under an inert atmosphere. A temperature of $700^{\circ} \mathrm{C}$ was optimum for achieving welldispersed Co NPs $9.0 \mathrm{~nm}$ in size, and the catalyst displayed nearly complete $\mathrm{AB}$ hydrolysis with a TOF of 5.6 $\mathrm{min}^{-1}$. However, the most remarkable feature of that 

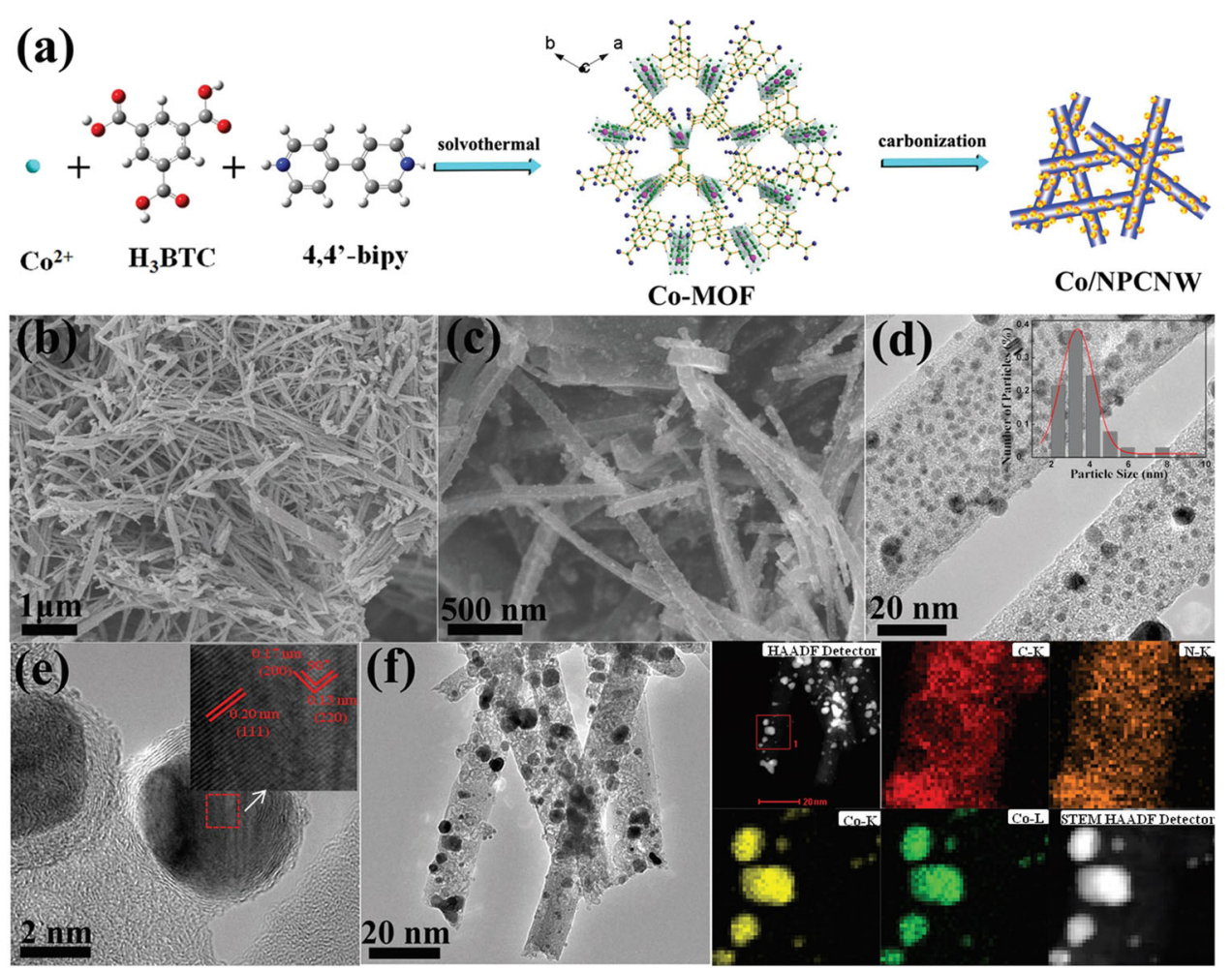

Fig. 9 (a) Conceptual schematic illustration of the synthetic route to Co/NPCNW. Morphology characterization: SEM (b and c), TEM (d), and highresolution TEM (HRTEM) (e) images of Co/NPCNW, the inset of (d) is the corresponding size distribution of cobalt nanoparticles, the inset of (e) is the magnification of the rectangular region. (f) STEM (HAADF, Co, C, N) elemental mapping images of Co/NPCNW. Reprinted with permission from Chen et al. ${ }^{66}$. Copyright@ 2017, Royal Society of Chemistry

catalyst was its stability; $97.2 \%$ of the initial activity was retained after 10 cycles. This research group recently expanded the investigation of Co catalysts with a new approach in which Co NPs of $3.5 \mathrm{~nm}$ were supported on an $\mathrm{N}$-doped porous carbon nanowires (Co/NPCNW) prepared via direct carbonization of $\mathrm{Co}-\mathrm{MOF}^{66}$. By following this procedure, Co cations were reduced to Co NPs and the carbon network was generated from the ligand, with the concomitant formation of $\mathrm{N}$-containing groups (see Fig. 9). This synthetic approach afforded welldistributed Co NPs as well as a steadily supported porous structure, which were favorable toward a high catalytic activity and stability with only a slight loss of $5.4 \%$ of the initial activity after 10 reaction runs.

Some interesting studies on Co-based bimetallic systems have been recently performed, with special attention paid to systems based on $\mathrm{Co}-\mathrm{Cu}$. Lee's group studied the performance of $\mathrm{Cu}_{\mathrm{x}} \mathrm{Co}_{1-\mathrm{x}} \mathrm{O}$ NPs on graphene oxide $\left(\mathrm{Cu}_{\mathrm{x}} \mathrm{Co}_{1-\mathrm{x}} \mathrm{O}-\mathrm{GO}\right)^{69}$. The optimization of the NP composition $\left(\mathrm{Cu}_{0.8} \mathrm{Co}_{0.2} \mathrm{O}-\mathrm{GO}\right)$ led to an unprecedented catalytic performance toward $\mathrm{AB}$ dehydrogenation for a non-noble metal-containing catalyst, reaching a TOF value of $70.0 \mathrm{~min}^{-1}$. In addition, an in situ XAS study on the $A B$ hydrolysis was reported for the first time to determine the electronic structure changes in the process. Zahmakiran and coworkers ${ }^{68}$ and Chen and coworkers ${ }^{76}$ also reported on the performance of carbon-supported $\mathrm{CuCo}$ alloy NPs.

\section{Ni-based catalyst}

Among the non-noble metal-based catalysts, Ni-based catalysts should be highlighted, not only for their suitability in the $A B$ dehydrogenation reaction, but also for their low cost and environmental friendliness ${ }^{70}$.

Chen's group reported the synthesis of $\mathrm{Ni} / \mathrm{C}$ from $\mathrm{Ni}-\mathrm{MOF}$ using three different experimental approaches (reduction with $\mathrm{KBH}_{4}(\mathrm{Ni} / \mathrm{C}-1)$, calcination at $700^{\circ} \mathrm{C}$ under $\operatorname{Ar}(\mathrm{Ni} / \mathrm{C}-2)$, and a combination of calcination and reduction $(\mathrm{Ni} / \mathrm{C}-3)^{77}$. As a result of these experimental conditions, Ni/C-1 showed agglomerated Ni NPs, while sample Ni/C-2 had surface-oxidized Ni NPs. Additionally, sample $\mathrm{Ni} / \mathrm{C}-3$, which was prepared via the reduction of sample $\mathrm{Ni} / \mathrm{C}-2$, encompassed features such as good dispersion and a suitable surface electronic state, which were helpful to achieve a high hydrogen release rate of $834 \mathrm{~mL} \mathrm{~min}^{-1} \mathrm{~g}^{-1}$ at room temperature. As seen for the 


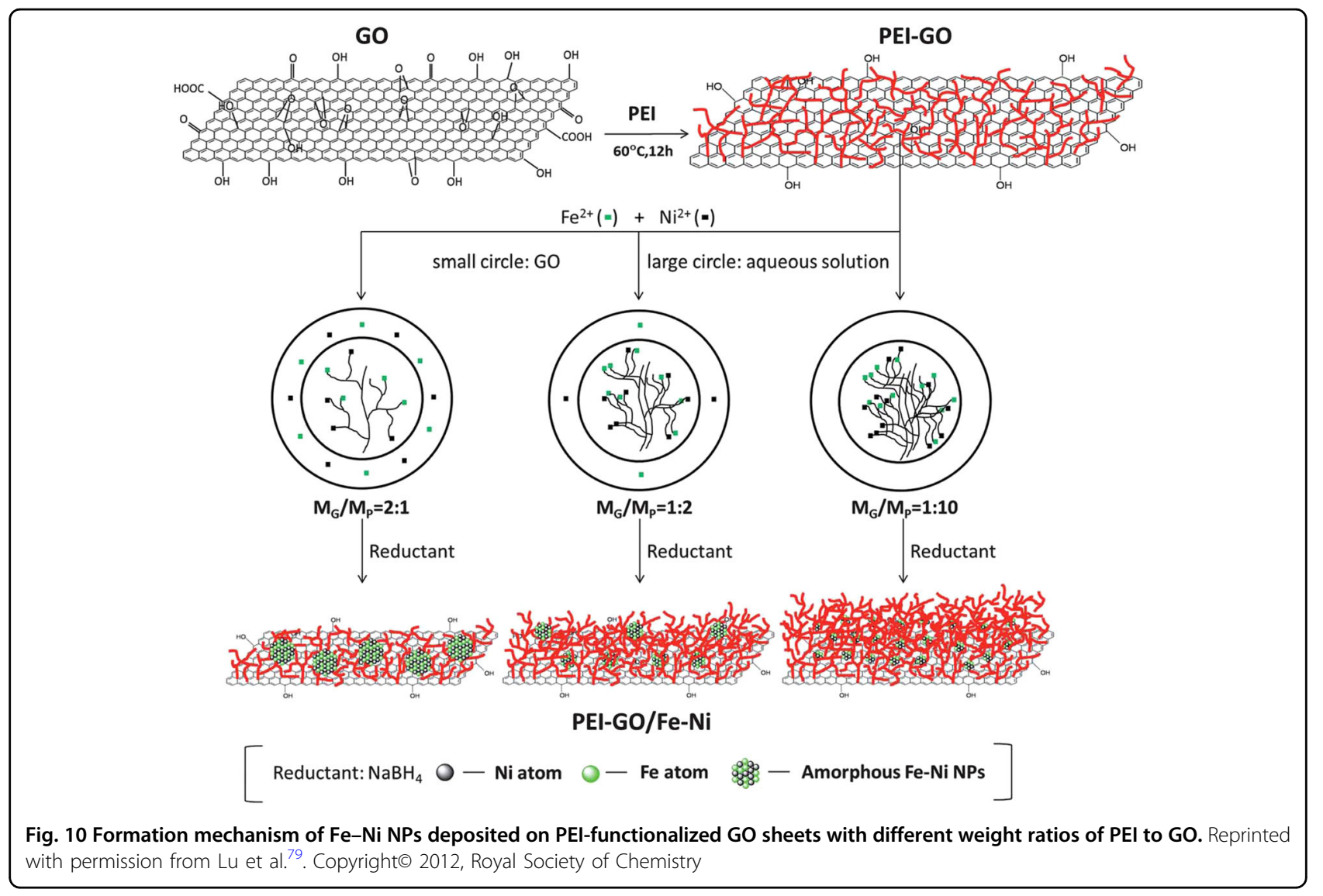

Pt catalysts previously mentioned ${ }^{56}$, Qin's group reported the use of ALD (atomic layer deposition) for the preparation of Ni/CNT nanocatalysts ${ }^{70}$ to note the importance of downsizing the Ni NPs. The results of the catalytic performance indicated that the sample with an average NP size of $5.6 \mathrm{~nm}$ (prepared by 200 ALD cycles) was the best-performing among those investigated. Nevertheless, the TOF number of this catalyst (26.2 $\mathrm{min}^{-1}$ ) did not exceed that previously reported by $\mathrm{Xu}$ using Ni@MSC-30 synthetized by a similar experimental method $\left(30.7 \mathrm{~min}^{-1}\right)^{71}$.

An improved performance was displayed by the catalysts studied by Shaabani and coworkers ${ }^{72}$, based on $\mathrm{Ni}$ NPs loaded onto three-dimensional N-doped graphenebased frameworks (NiNPs@3D-(N)GFs). The effect of N and $\mathrm{Ni}$ contents revealed optimum values for 3.65 and $11.0 \%$, respectively, with which the $\mathrm{AB}$ dehydrogenation was completed in $8 \mathrm{~min}$ with a TOF of $41.7 \mathrm{~min}^{-1}$.

By using bimetallic NPs, Kim reported on the performance of $\mathrm{NiCu}$ nanorods incorporated on carbon nanofibers (NiCu nanorods@C nanofibers) and highlighted the good stability of the catalyst, which retained its initial activity following six cycles ${ }^{78}$. A different system based on $\mathrm{Fe}-\mathrm{Ni} \mathrm{NPs}$ on polyethyleneimine (PEI)-decorated graphene oxide was reported by $\mathrm{Lu}(\mathrm{PEI}-\mathrm{GO} / \mathrm{Fe}-\mathrm{Ni})^{79}$. The methodology used in that case was claimed to be effective for controlling the $\mathrm{Fe}-\mathrm{Ni} \mathrm{NP}$ size and morphology by modifying the PEI content attached to the GO surface. It was shown that for a small PEI content, most of the metal ions nucleated in the bulk solution and subsequently deposited on GO, resulting in aggregation, while for higher PEI content, more ions were sequestered from the solution, and the nucleation and growth process occurred within the attached PEI layers, therefore resulting in the synthesis of small NPs $(3 \mathrm{~nm})$ (see Fig. 10). This system showed high activity with a dehydrogenation rate of 982 $\mathrm{mL} \min ^{-1} \mathrm{~g}^{-1}$ at $25^{\circ} \mathrm{C}$.

\section{Future directions}

The promising results recently attained by the use of chemical hydrogen storage molecules as well as the versatility of carbon materials introduce many alternatives in order to achieve high-performance heterogeneous catalysts to boost the hydrogen production from formic acid and ammonia-borane. Despite the great efforts paid by the research community during the past decade in the design and synthesis of high-performance carbon-supported metal-based catalysts, there is still room for improving the approach for future investigations. One of the principal drawbacks of the catalytic 
systems studied thus far is their insufficient stability under the reaction conditions; therefore, the optimization of the catalytic features should aim at improving this aspect while preserving the nanoparticle surface availability. In light of breakthroughs achieved thus far by modulating the metal-support interaction by using $\mathrm{N}$ doped carbon materials, the functionalization of carbon materials using other doping candidates (i.e., boron, sulfur, and phosphorus) would be an interesting approach in future investigations, and could be expected to be a useful tool to fine-tune the supported nanoparticles features and to prevent the nanoparticles from sintering and leaching, which are all relevant factors closely linked with the catalytic durability. Concerning the metallic active phase composition, non-noble metal catalysts are emerging as an interesting alternative to the commonly used noble metal-based catalysts, particularly in the case of the ammonia-borane dehydrogenation reaction. However, although the utilization of non-noble metal catalysts is increasingly investigated, future studies should be focused on the design, scalability, and environmentally friendliness of the synthesis methods of affordable noble metal-free catalysts able to display competitive performances under the reaction conditions.

\section{Conclusions}

This review summarizes some of the most relevant recent approaches toward carbon-supported metal catalysts for hydrogen production from formic acid and ammonia-borane, with attention on the most widely investigated active phases. In the case of formic acid, the supremacy of Pd-based catalysts is highlighted by recapitulating the most recent achievements made by using monometallic and bimetallic Pd-based catalytic systems, while highlighting the importance of the active phase features, such as the nanoparticle size, electronic features, and composition, as well as the support functionalization and presence of additives in the reaction medium. Additionally, the active phases utilized to catalyze the ammonia-borane dehydrogenation reaction are much more diverse, but the importance of Ru-based systems should be highlighted. Nevertheless, remarkable accomplishments with non-noble metal catalysts have been achieved, and even though their catalytic activity is not as high as those of noble metal catalysts, their interest is undeniable. The review of these studies demonstrates that, even though significant advancements of the knowledge of high-performance heterogeneous catalysts for hydrogen production from formic acid and ammonia-borane have been realized, further investigation is needed to design catalysts able to meet the practical application criteria (efficiency, cost, and reusability), and carbon materials will remain essential because their tunable features and versatility offer innumerable synthetic approaches.

\section{Acknowledgements}

This research was partially supported by JST, PRESTO (JPMJPR1544). The present work was also supported by Grants-in-Aid for Scientific Research (Nos. 26220911, 25289289, and 26630409, 26620194) from the Japan Society for the Promotion of Science (JSPS) and MEXT and "Elemental Strategy Initiative to Form Core Research Center." Miriam Navlani-García thanks JSPS for the Postdoctoral Fellowship.

\section{Author details}

${ }^{1}$ Division of Materials and Manufacturing Science, Graduate School of Engineering, Osaka University, 2-1 Yamada-oka, Suita, Osaka 565-0871, Japan. 2JST, PRESTO, 4-1-8 Honcho, Kawaguchi, Saitama 332-0012, Japan. ${ }^{3}$ Unit of Elements Strategy Initiative for Catalysts \& Batteries, Kyoto University, Katsura, Kyoto 615-8520, Japan

\section{Conflict of interest}

The authors declare that they have no conflict of interest.

\section{Publisher's note}

Springer Nature remains neutral with regard to jurisdictional claims in published maps and institutional affiliations.

Received: 27 September 2017 Revised: 06 December 2017 Accepted: 04 February 2018.

Published online: 17 April 2018

\section{References}

1. Sartbaeva, A., Kuznetsov, V. L., Wells, S. A. \& Edwards, P. P. Hydrogen nexus in a sustainable energy future. Energy Environ. Sci. 1, 79-85 (2008).

2. Lai, Q. et al. Hydrogen storage materials for mobile and stationary applications: current state of the art. ChemSusChem 8, 2789-2825 (2015).

3. Edwards, P. P., Kuznetsov, V. L., David, W. I. F. \& Brandon, N. P. Hydrogen and fuel cells: towards a sustainable energy future. Energy Policy 36, 4356-4362 (2008).

4. Joó, F. Breakthroughs in hydrogen storage-formic acid as a sustainable storage material for hydrogen. ChemSusChem 1, 805-808 (2008).

5. Navlani-García, M. et al. Pd/zeolite-based catalysts for the preferential CO oxidation reaction: ion-exchange, Si/Al and structure effect. Catal. Sci. Technol. 6. 2623-2632 (2016)

6. van den Berg, A. W. C. \& Areán, C. O. Materials for hydrogenstorage: current research trends and perspectives. Chem. Commun. 668-681 (2008).

7. Steele, B. C. H. \& Heinzel, A. Materials for fuel-cell technologies. Nature 414, 345-352 (2001).

8. Eberle, U., Felderhoff, M. \& Schüth, F. Chemical and physical solutions for hydrogen storage. Angew. Chem. Int. Ed. 48, 6608-6630 (2009).

9. Dalebrook, A. F., Gan, W., Grasemann, M., Moret, S. \& Laurenczy, G. Hydrogen storage: beyond conventional methods. Chem. Commun. 49, 8735-8751 (2013).

10. Rodríguez-Reinoso, F. \& Seṕulveda-Escribano, A. in Carbon Materials for Catalysis (ed. Serp, F. \& Figuereido, J. L.) Ch. 4, 131-155 (John Wiley \& Sons, Inc., Hoboken, NJ, USA, 2009).

11. Williams, R., Crandall, R. S. \& Bloom, A. Use of carbon dioxide in energy storage. Appl. Phys. Lett. 33, 381-383 (1978).

12. Singh, A. K., Singh, S. \& Kumar, A. Hydrogen energy future with formic acid: a renewable chemical hydrogen storage system. Catal. Sci. Technol. 6, 12-40 (2015).

13. Targets for Onboard Hydrogen Storage Systems for Light-Duty Vehicles, U.S Department of Energy, Office of Energy Efficiency and Renewable Energy, http://energy.gov/eere/fuelcells/downloads/doetargets-onboard-hydrogenstorage-systems-light-duty-vehicles.

14. Zhao, Y. et al. Selective decomposition of formic acid over immobilized catalysts. Energy Fuels. 25, 3693-3697 (2011). 
15. Wang, Z. L., Yan, J. M., Wang, H. L., Ping, Y. \& Jiang, Q. Pd/C synthesized with citric acid: an efficient catalyst for hydrogen generation from formic acid/ sodium formate. Sci. Rep. 2, 1-6 (2012).

16. Jiang, K., Xu, K., Zou, S. \& Cai, W. B-doped pd catalyst: Boosting roomtemperature hydrogen production from formic acid-formate solutions. J. Am. Chem. Soc. 136, 4861-4864 (2014).

17. Bi, Q.-Y. et al. Dehydrogenation of formic acid at room temperature: boosting palladium nanoparticle efficiency by coupling with pyridinic-nitrogen-doped carbon. Angew. Chem. Int. Ed. 55, 11849-11853 (2016).

18. Li, J. et al. Size-dependent catalytic activity over carbon-supported palladium nanoparticles in dehydrogenation of formic acid. J. Catal. 352, 371-381 (2017).

19. Wang, $X$. et al. $\mathrm{Pd} / \mathrm{C}$ nanocatalyst with high turnover frequency for hydrogen generation from the formic acid-formate mixtures. Int. J. Hydrog. Energy 39, 837-843 (2014).

20. Zhang, S., Jiang, B., Jiang, K. \& Cai, W.-B. Surfactant-free synthesis of carbonsupported palladium nanoparticles and size-dependent hydrogen production from formic acid-formate solution. ACS Appl. Mater. Interfaces 9, 24678-24687 (2017).

21. Jeon, M. et al. Electronically modified Pd catalysts supported on N-doped carbon for the dehydrogenation of formic acid. Int. J. Hydrog. Energy 41 15453-15461 (2016).

22. Zhu, Q.-L., Tsumori, N. \& Xu, Q. Sodium hydroxide-assisted growth of uniform $\mathrm{Pd}$ nanoparticles on nanoporous carbon MSC-30 for efficient and complete dehydrogenation of formic acid under ambient conditions. Chem. Sci. 5, 195-199 (2014).

23. Zhou, J. P., Zhang, J., Dai, X. H., Wang, X. \& Zhang, S. Y. Formic acid-ammonium formate mixture: a new system with extremely high dehydrogenation activity and capacity. Int. J. Hydrog. Energy 41, 22059-22066 (2016).

24. Zhu, Q. L., Tsumori, N. \& Xu, Q. Immobilizing extremely catalytically active palladium nanoparticles to carbon nanospheres: a weakly-capping growth approach. J. Am. Chem. Soc. 137, 11743-11748 (2015).

25. Li, Z. et al. Tandem nitrogen functionalization of porous carbon: toward immobilizing highly active palladium nanoclusters for dehydrogenation of formic acid. ACS Catal. 7, 2720-2724 (2017)

26. Tedsree, $\mathrm{K}$. et al. Hydrogen production from formic acid decomposition at room temperature using a Ag-Pd core-shell nanocatalyst. Nat. Nanotechnol. 6 , 302-307 (2011).

27. Huang, Y. et al. An effective low Pd-loading catalyst for hydrogen generation from formic acid. Int. J. Hydrog. Energy 42, 18375-18382 (2017).

28. Nabid, M. R., Bide, Y. \& Etemadi, B. Ag@Pd nanoparticles immobilized on a nitrogen-doped graphene carbon nanotube aerogel as a superb catalyst for the dehydrogenation of formic acid. New J. Chem. https://doi.org/10.1039/ C7NJ01108C. (2017).

29. Yang, L. et al. Highly efficient hydrogen generation from formic acid-sodium formate over monodisperse AgPd nanoparticles at room temperature. Appl. Catal. B Environ. 168-169, 423-428 (2015).

30. Feng, C., Wang, Y., Gao, S., Shang, N. \& Wang, C. Hydrogen generation at ambient conditions: AgPd bimetal supported on metal-organic framework derived porous carbon as an efficient synergistic catalyst. Catal. Commun. 78, 17-21 (2016).

31. Zhang, S., Metin, Ö., Su, D. \& Sun, S. Monodisperse AgPd alloy nanoparticles and their superior catalysis for the dehydrogenation of formic acid. Angew. Chem. Int. Ed. 52, 3681-3684 (2013).

32. Navlani-García, M., Mori, K., Nozaki, A., Kuwahara, Y. \& Yamashita, H. Screening of carbon-supported PdAg nanoparticles in the hydrogen production from formic acid. Ind. Eng. Chem. Res. 55, 7612-7620 (2016).

33. Wu, S., Yang, F., Sun, P. \& Chen, T. Au-Pd alloy catalyst with high performance for hydrogen generation from formic acid-formate solution at nearly $0{ }^{\circ} \mathrm{C}$. RSC Adv. 4, 44500-44503 (2014).

34. Wang, Z.-L. et al. Facile synthesis of nitrogen-doped graphene supported AuPd-CeO2 nanocomposites with high-performance for hydrogen generation from formic acid at room temperature. Nanoscale 6, 3073-7 (2014).

35. Wang, Z.-L., Yan, J.-M., Wang, H.-L., Ping, Y. \& Jiang, Q. Au@Pd core-shell nanoclusters growing on nitrogen-doped mildly reduced graphene oxide with enhanced catalytic performance for hydrogen generation from formic acid. J. Mater. Chem. A 1, 12721-12725 (2013).

36. Metin, Ö., Sun, X. \& Sun, S. Monodisperse gold-palladium alloy nanoparticles and their composition-controlled catalysis in formic acid dehydrogenation under mild conditions. Nanoscale 5, 910-912 (2013).
37. Zhou, X. et al. Available hydrogen from formic acid decomposed by rare earth elements promoted Pd-Au/C catalysts at low temperature. ChemSusChem $\mathbf{3}$ 1379-1382 (2010)

38. Cheng, J., Gu, X., Sheng, X., Liu, P. \& Su, H. Exceptional size-dependent catalytic activity enhancement in the room-temperature hydrogen generation from formic acid over bimetallic nanoparticles supported by porous carbon. J. Mater. Chem. A 4, 1887-1894 (2016).

39. $\mathrm{Wu}, \mathrm{S}$. et al. $\mathrm{Mg}^{2+}$-assisted low temperature reduction of alloyed $\mathrm{AuPd} / \mathrm{C}$ : an efficient catalyst for hydrogen generation from formic acid at room temperature. Chem. Commun. 51, 10887-10890 (2015).

40. Jeon, Hjin \& Chung, Y. M. Hydrogen production from formic acid dehydrogenation over Pd/C catalysts: Effect of metal and support properties on the catalytic performance. Appl. Catal. B Environ. 210, 212-222 (2017).

41. Bulushev, D. A. et al. Single isolated $\mathrm{Pd}^{2+}$ cations supported on N-doped carbon as active sites for hydrogen production from formic acid decomposition. ACS Catal. 6, 681-691 (2016).

42. Peng, B., Wang, H.-F., Liu, Z.-P. \& Cai, W.-B. Combined surface-enhanced infrared spectroscopy and first-principles study on electro-oxidation of formic acid at Sb-modified Pt electrodes. J. Phys. Chem. C 114, 3102-3107 (2010)

43. Gao, W., Keith, J. A., Anton, J. \& Jacob, T. Theoretical elucidation of the competitive electro-oxidation mechanisms of formic acid on Pt(111). J. Am. Chem. Soc. 132, 18377-18385 (2010).

44. Jia, L., Bulushev, D. A., Beloshapkin, S. \& Ross, J. R. H. Hydrogen production from formic acid vapour over a $\mathrm{Pd} / \mathrm{C}$ catalyst promoted by potassium salts: evidence for participation of buffer-like solution in the pores of the catalyst. Appl. Catal. B Environ. 160-161, 35-43 (2014).

45. Liu, D., Gao, Z. Y., Wang, X. C., Zeng, J. \& Li, Y. M. DFT study of hydrogen production from formic acid decomposition on $\mathrm{Pd}-\mathrm{Au}$ alloy nanoclusters. Appl. Surf. Sci. 426, 194-205 (2017).

46. Yang, L. et al. Highly efficient hydrogen generation from formic acid-sodium formate over monodisperse AgPd nanoparticles at room temperature. Appl. Catal. B Environ. 168-169, 423-428 (2015).

47. Wang, W. et al. Highly active carbon supported Pd-Ag nanofacets catalysts for hydrogen production from $\mathrm{HCOOH}$. Appl. Mater. Interfaces 8, 20839-20848 (2016).

48. Zhou, X. et al. High-quality hydrogen from the catalyzed decomposition of formic acid by Pd-Au/C and Pd-Ag/C. Chem.Commun. 0 3540-3542 (2008).

49. Qin, Y., Wang, J., Wu, Y. \& Wang, L. Improved hydrogen production from formic acid under ambient conditions using a PdAu catalyst on a graphene nanosheets-carbon black support. RSC Adv. 4, 30068-30073 (2014).

50. Zhu, Q. L. \& Xu, Q. Liquid organic and inorganic chemical hydrides for highcapacity hydrogen storage. Energy Environ. Sci. 8, 478-512 (2015).

51. Hamilton, C. W., Baker, R. T., Staubitz, A. \& Manners, I. B-N compounds for chemical hydrogenstorage. Chem. Soc. Rev. 38, 279-293 (2009).

52. Ryschkewitsch, G. E. Amine boranes. I. Kinetics of acid hydrolysis of trimethylamine borane. J. Am. Chem. Soc. 82, 3290-3294 (1960).

53. Chandra, M. \& Xu, Q. A high-performance hydrogen generation system: transition metal-catalyzed dissociation and hydrolysis of ammonia - borane. J. Power Sources 156, 190-194 (2006).

54. Akbayrak, S. \& Özkar, S. Ruthenium(0) nanoparticles supported on multiwalled carbon nanotube as highly active catalyst for hydrogen generation from ammonia-borane. ACS Appl. Mater. Interfaces 4, 6302-6310 (2012).

55. Wang, X., Liu, D., Song, S. \& Zhang, H. Graphene oxide induced formation of Pt-CeO2 hybrid nanoflowers with tunable $\mathrm{CeO} 2$ thickness for catalytic hydrolysis of ammonia borane. Chem. A Eur. J. 19, 8082-8086 (2013).

56. Zhang, J. et al. Highly dispersed Pt nanoparticles supported on carbon nanotubes produced by atomic layer deposition for hydrogen generation from hydrolysis of ammonia borane. Catal. Sci. Technol. 7, 322-329 (2017).

57. Chen, W. et al. Unique reactivity in Pt/CNT catalyzed hydrolytic dehydrogenation of ammonia borane. ChemComm 50, 2142-2144 (2014).

58. Cao, N., Luo, W. \& Cheng, G. One-step synthesis of graphene supported Ru nanoparticles as efficient catalysts for hydrolytic dehydrogenation of ammonia borane. Int. J. Hydrog. Energy 38, 11964-11972 (2013).

59. Liang, $\mathrm{H}$. et al. In situ facile synthesis of ruthenium nanocluster catalyst supported on carbon black for hydrogen generation from the hydrolysis of ammonia-borane. Int. J. Hydrog. Energy 37, 17921-17927 (2012).

60. Du, C. et al. Facile synthesis of monodisperse ruthenium nanoparticles supported on graphene for hydrogen generation from hydrolysis of ammonia borane. Int. J. Hydrog. Energy 40, 6180-6187 (2015). 
61. Fernandes, R. et al. Ruthenium nanoparticles supported over carbon thin film catalyst synthesized by pulsed laser deposition for hydrogen production from ammonia borane. Appl. Catal. A Gen. 495, 23-29 (2015).

62. Navlani-Garcia, M., Mori, K., Nozaki, A., Kuwahara, Y. \& Yamashita, H. Highly efficient Ru/carbon catalysts prepared by pyrolysis of supported Ru complex towards the hydrogen production from ammonia borane. Appl. Catal. A Gen. 527, 45-52 (2016)

63. Cao, N., Hu, K., Luo, W. \& Cheng, G. RuCu nanoparticles supported on graphene: a highly efficient catalyst for hydrolysis of ammonia borane. J. Alloy Compd. 590, 241-246 (2014)

64. Cao, N., Su, J., Luo, W. \& Cheng, G. Hydrolytic dehydrogenation of ammonia borane and methylamine borane catalyzed by graphene supported Ru@Ni core-shell nanoparticles. Int. J. Hydrog. Energy 39, 426-435 (2014).

65. Wang, H., Zhao, Y., Cheng, F., Tao, Z. \& Chen, J. Cobalt nanoparticles embedded in porous $\mathrm{N}$-doped carbon as long-life catalysts for hydrolysis of ammonia borane. Catal. Sci. Technol. 6, 3443-3448 (2016).

66. Zhou, L. et al. Ultrasmall cobalt nanoparticles supported on nitrogen-doped porous carbon nanowires for hydrogen evolution from ammonia borane. Mater. Horiz. 4, 268-273 (2017).

67. Li, M., Hu, J. \& Lu, H. A stable and efficient 3D cobalt-graphene composite catalyst for the hydrolysis of ammonia borane. Catal. Sci. Technol. 6, 7186-7192 (2016).

68. Bulut, A. et al. Carbon dispersed copper-cobalt alloy nanoparticles: a costeffective heterogeneous catalyst with exceptional performance in the hydrolytic dehydrogenation of ammonia-borane. Appl. Catal. B Environ. 180 121-129 (2016)

69. Feng, $\mathrm{K}$. et al. CuxCo1-xO nanoparticles on graphene oxide as a synergistic catalyst for high-efficiency hydrolysis of ammonia-borane. Angew. Chem. Int Ed. 55, 11950-11954 (2016).

70. Zhang, J. et al. Ni nanoparticles supported on CNTs with excellent activity produced by atomic layer deposition for hydrogen generation from the hydrolysis of ammonia borane. Catal. Sci. Technol. 6, 2112-2119 (2016).
71. Li, P. Z., Aijaz, A. \& Xu, Q. Highly dispersed surfactant-free nickel nanoparticles and their remarkable catalytic activity in the hydrolysis of ammonia borane for hydrogen generation. Angew. Chem. Int. Ed. 51, 6753-6756 (2012).

72. Mahyari, M. \& Shaabani, A. Nickel nanoparticles immobilized on threedimensional nitrogen-doped graphene as a superb catalyst for the generation of hydrogen from the hydrolysis of ammonia borane. J. Mater. Chem. A 2 16652-16659 (2014)

73. Chen, W., Duan, X., Qian, G., Chen, D. \& Zhou, X. Carbon nanotubes as support in the platinum-catalyzed hydrolytic dehydrogenation of ammonia borane. ChemsusChem 8, 2927-2931 (2015).

74. Chen, W. et al. Mechanistic insight into size-dependent activity and durability in Pt/CNT catalyzed hydrolytic dehydrogenation of ammonia borane. J. Am. Chem. Soc. 136, 16736-16739 (2014).

75. Wu, Z. et al. Promoting hydrolysis of ammonia borane over multiwalled carbon nanotube-supported Ru catalysts via hydrogen spillover. Catal. Commun. 91, 10-15 (2017).

76. Wang, $\mathrm{H}$. et al. CuCo nanoparticles supported on hierarchically porous carbon as catalysts for hydrolysis of ammonia borane. J. Alloy. Compd. 651, 382-388 (2015).

77. Zhou, L., Zhang, T., Tao, Z. \& Chen, J. Ni nanoparticles supported on carbon as efficient catalysts for the hydrolysis of ammonia borane. Nano Res. 7, 774-781 (2014).

78. Yousef, A., Barakat, N. A. M., El-Newehy, M. \& Kim, H. Y. Chemically stable electrospun NiCu nanorods@carbon nanofibers for highly efficient dehydrogenation of ammonia borane. Int. J. Hydrog. Energy 37, 17715-17723 (2012).

79. Zhou, X., Chen, Z., Yan, D. \& Lu, H. Deposition of Fe-Ni nanoparticles on polyethyleneimine-decorated graphene oxide and application in catalytic dehydrogenation of ammonia borane. J. Mater. Chem. 22, 13506 (2012). 